Bond University

Research Repository

\title{
The Color of Choice: The Influence of Presenting Product Information in Color on the Compromise Effect
}

Kim, Jungkeun ; Spence, Mark T.; Marshall, Roger

Published in:

Journal of Retailing

DOI:

10.1016/j.jretai.2018.01.002

Licence:

CC BY-NC-ND

Link to output in Bond University research repository.

Recommended citation(APA):

Kim, J., Spence, M. T., \& Marshall, R. (2018). The Color of Choice: The Influence of Presenting Product Information in Color on the Compromise Effect. Journal of Retailing, 94(2), 167-185.

https://doi.org/10.1016/j.jretai.2018.01.002

\section{General rights}

Copyright and moral rights for the publications made accessible in the public portal are retained by the authors and/or other copyright owners and it is a condition of accessing publications that users recognise and abide by the legal requirements associated with these rights.

For more information, or if you believe that this document breaches copyright, please contact the Bond University research repository coordinator 


\title{
The Color of Choice:
}

\section{The Influence of Presenting Product Information in Color on the Compromise Effect}

\begin{abstract}
Consumers often find themselves challenged by the conflicting desires to seek uniqueness versus conformity, and thus seek some degree of balance. In a series of six studies we show that presenting each options' product-related information in a unique color, as opposed to all product-related information presented in black-on-white, partially satiates the desire for uniqueness, thus amplifying the compromise effect. Consumers facing color presentation formats choose the middle, conforming option more often, yet perceive their choice as more unique. This color effect is not realized if each option's attributes are presented in different colors, but all options use a consistent color scheme, as is often the case in on-line retailing sites such as Amazon.com. Having to justify one's choice moderates the color effect. The practical take-away is that consumers' choices can be influenced by using unique colors to present option-related product information, a variable that is entirely independent of the options' performance characteristics. Two field studies confirm this finding, one using a plain background versus a colored background in a product display and the other using product containers that are either in plain white or wrapped in unique colors.
\end{abstract}

Keywords: compromise effect, color effect, uniqueness versus conformity, consumer motivation theory 


\section{AN INTERESTING PHENOMENON}

The basic color options for iPhone 6 and 6S are silver, gold, rose-gold, and gray/black. Apple added two new, distinctive color options of red and jet-black to the iPhone 7 and 7Plus series, each of which is available in three memory sizes. It seemed odd to find out from a large telecom company that the middle memory option was by far the most popular for those that chose one of the two new iPhone colors, whereas memory option preference was spread more evenly for those that selected one of the original colors of silver, gold, rose-gold and gray/black.

The researchers investigated this unexpected sales pattern statistically. The detailed iPhone sales data came from one of three major mobile carrier companies in South Korea over the period October 21, 2016 to February 20, 2017. The total number of new iPhones sold by the carrier company during this period was 176,563. All customers had access to the array of six colors. Two groups were formed for analysis: customers that selected one of the original color options of black, gold, rose-gold or silver, and the other group of customers who chose one of the two new, distinctive color options of red or jet-black. The results of the statistical investigation of whether color and memory size are seemingly related yields intriguing support. The preference for choosing the middle size memory (128GB out of 32GB, $128 \mathrm{~GB}$ and $256 \mathrm{~GB}$ ) is much higher for those who chose one of the new colored options $(79.78 \%(55,866 / 70,021))$ than for those who chose the original colored options $(68.95 \%$ $\left.(73,466 / 106,542), x^{2}(1)=2528.98, p<.0001\right)$. Furthermore, this pattern is the same regardless of which version of iPhone is considered: iPhone7 $(75.99 \%(30,542 / 40,190)$ vs. $\left.64.20 \%(46,242 / 72,029), x^{2}(1)=1661.02, p<.0001\right)$ or iPhone 7 Plus $(84.89 \%$ $(25,324 / 29,831)$ vs. $\left.78.88 \%(27,224 / 34,513), x^{2}(1)=386.17, p<.0001\right)$. The question that 
immediately springs to mind is: could this pattern of sales be explained by the new, different, color options that iPhone introduced?

Consumers are regularly exposed to colorful content, not only in the images that they see, such as in-store products, brands in magazines, papers and on websites, but also in the surrounding print (Coyle and Thorson 2001; Rosenkrans 2009). For instance, consumers who want to buy a camera on Amazon.com will see thumbnail pictures of the various product offerings, as shown in Appendix A. Based on different search keywords, the search shows different results in that the suggested products are mostly black (as in searching "DSLR camera") or many different colors (as in "digital camera" search). In addition, the products will feature brand-related information, often presented using a mixture of fonts and colors. The brand name and key feature(s) might be in blue, price is often displayed in red, and customer ratings may be in yellow. Regardless of the color or combination of colors used, we suggest that varying the color of brand-related information across options such that each brand has its own unique color scheme will influence consumers' choices.

Existing research already provides some insight regarding the impact of color on decision making and information processing. For example, Bellizzi and Hite (1992) found that blue generates more positive responses in a retailing setting than does red, and Bagchi and Cheema (2013) show that using these colors as backgrounds in on-line auction sites affects bidding behavior. For instance, a red background induces aggression, which leads to higher bid jumps in an auction, but to lower price offers in negotiations. At a brand level, Labrecque and Milne (2012) discuss the impact of color on brand perceptions, such as red generating an exciting brand image and blue a competent one. Kress and Van Leeuwen (2002) provide a summary of the semiotic aspects of color associations.

In the research reported here we explore how altering the color of brand-related information in an on-line B2C environment, such that each brand has a unique color, 
influences consumers' motivations and, consequently, their choices from a compromise effect perspective. Thus, in contrast to the aforementioned studies, we are not interested in how a specific color per se affects behavior (see, e.g., Bagchi and Cheema, 2013; Bellizzi and Hite, 1992; Kress and Van Leeuwen, 2002; Labrecque and Milne, 2012), but rather how the mere presence of using different, unique colors alters the balance of internal motivations, and hence choices from a compromise effect perspective. This is the issue addressed here, both theoretically and empirically.

Consumer motivation theory suggests that consumers have two important, but often conflicting, motivations that they endeavor to balance when decision-making, the needs for uniqueness and conformity (Hornsey and Jetten 2004; Nail 1986; Tian, Bearden, and Hunter 2001; Maimaran and Simonson, 2011). Our main theoretical contribution is that using different colors to present option-related information partially satiates the need for uniqueness, thus amplifying the need for conformity - choosing the middle option - and hence increasing the compromise effect. Confirming this supposition in controlled settings has clear, practical import. The key take-away is that presenting each option in a unique color scheme affects consumers' choices, an insight relevant to both offline and online retailers that currently use a consistent color scheme across all options, as is the case, for example, on some pages of Amazon.com and TripAdvisor.com.

This paper is organized as follows. First, we review two separate literature streams, one pertaining to the compromise effect and the other the effect of color on consumer decision-making. By linking these literature streams we develop our key hypothesis, that the compromise effect will be greater if each brand uses a unique color to present relevant information compared to all brands using black-on-white font. USA-based survey findings are then presented that confirm that the retail sales of the Korean telecom company are not caused by some local phenomenon, such as some ethnic or competitive bias, and that there is a 
relationship between the need for uniqueness and the strength of the "color compromise" effect. Three laboratory and two field experiments are then presented. Empirical findings provide evidence that the compromise effect is amplified if brand-related information is presented in different colors as opposed to black-on-white (or all options using an identical color scheme), and that consumer motivation theory rather than cognitive resource-based theory accounts for this outcome. Finally, we summarize our findings and discuss the theoretical and practical implications of our research.

\section{THEORETICAL FRAMEWORK AND HYPOTHESIS}

The compromise effect refers to the higher probability of an option being selected when it is positioned in an intermediate position in a choice set of three (Simonson, 1989), a finding broadly supported despite some criticism (Bettman, Luce, \& Payne, 1998; Chernev, 2004; Simonson \& Tversky, 1992). Research has focused on investigating potential antecedents and moderators affecting the magnitude of the compromise effect, such as time pressure, regulatory focus, reference groups, physical balance and product category (Dhar \& Simonson, 2003; Larson \& Billeter, 2013; Kim and Kim 2015; Mourali et al., 2007). Thus, for example, Mourali et al. (2007) show that, compared with promotion-focused individuals, prevention-focused individuals prefer the compromise option more in order to reduce the potential risks associated with making a poor choice. More recently, Kim and Kim (2015) found that the type of product moderates the magnitude of the compromise effect, in that the compromise effect is stronger for utilitarian products than for hedonic products.

How information is presented also affects the compromise effect. For example, Nowlis and Simonson (2000) demonstrated that in contexts featuring brands of different price-quality tiers, the compromise effect is weakened when the low price-quality option is 
actively promoted, as this provides a reason for choosing it. Novemsky et al. (2007) found that individuals who have difficulty reading the font of the various options choose the compromise option more often than those who experienced no difficulty - or simply deferred the decision. The authors concluded that this is because individuals attribute the difficulty of processing the information to choice difficulty, rather than difficulty in reading the information.

Thus, research has unearthed factors that influence the compromise effect, but little is known about how the color of option-related information affects the compromise effect given no other change to the choice set or the options' attributes. This lack of insight seems odd considering that dominant online websites often use all one color to present text, or use a consistent color combination across options. We argue that changing the colors of brandrelated information will affect consumers' choices.

\section{The effect of color on decision making}

Research concerning the effect of color on decision making has featured prominently in consumer behavior, such as how color affects price perceptions (Puccinelli et al., 2013), consumers' feelings and purchase intentions (Belizzi and Hite, 1992), moral judgments (De Bock, Pandelaere, and Kenhove, 2013), brand personality (Labrecque and Milne, 2010), and advertising perceptions (Wedel and Pieters 2014). For example, red is associated with price discounts and savings (Puccinelli et al., 2013). Red also affects one's approach/avoidance orientation. Elliot et al. (2007) found that even a brief exposure to red prior to a test impairs performance, because red is associated with danger and hence evokes an avoidance motivation. Bagchi and Cheema (2013) found that red backgrounds on auction sites are more arousing than blue, and hence results in more aggressive bid jumps. Despite these interesting insights, this paper is not about the effect of specific colors. 
Closer to this study's purpose, Lee et al., (2014) investigated how the presence or absence of color affects how people construe information. Across a series of studies these authors found that black-and-white images are processed at a high construal level, whereas color images are processed at a lower construal level. This, in turn, affects how individuals sort objects (on high-level versus low-level features), and how they weigh product features (placing more weight on primary versus secondary features). Another study investigating the effect of color on information processing concluded that colored information requires greater cognitive resources during encoding (Meyers-Levy and Peracchio, 1995). Breitmeyer, Ogmen, and Chen (2004) argue that people process an object's color information at a relatively early stage, before processing other information. We assume that color is different from the other product information, and will elaborate upon these insights later.

The research reported here investigates the impact on brand choice of using colored rather than black-on-white fonts to describe brand attributes, holding all else constant. We are not interested in whether associations for a specific color affect choice - indeed, Study 2 specifically rules that out - but rather endeavor to show that the magnitude of the compromise effect is increased when each brand uses a unique color font compared to the same options having their features presented in black-on-white only or all options using an identical color scheme. On-line retailers often use a mix of colors (see, e.g., Amazon.com or TripAdvisor.com), but each of the options uses an identical color scheme.

\section{The impact of color on the compromise effect}

We assume that choosing an extreme (versus middle) option in a compromise set is related to pursuing the uniqueness (conformity) motivation. This assumption is supported not only by the crude survey research reported earlier, but also by previous published research by Kim and Drolet (2003). They provided empirical evidence that choosing the middle option in 
a repeated choice task was higher for Korean-born participants (who value conformity) rather than the US-born (who compared to Koreans value uniqueness). In addition, Simonson and Nowlis (2000) provide a similar result in that people in high (low) need for uniqueness condition tend to choose the extreme (middle) option of three.

We propose that a stronger compromise effect will occur when each brand has its own color, rather than all brands using black-on-white, when presenting product related information. Two different explanations lend support for this prediction. The first draws from consumer motivation theory (Hornsey and Jetten 2004; Nail 1986; Tian, Bearden, and Hunter 2001). Snyder and Fromkin (1977, p. 518) define uniqueness as "a positive striving for differentness relative to other people.” Tian, Bearden, and Hunter (2001, p. 52) similarly define the uniqueness motivation in consumption as "a motivation for differentiating the self through consumer goods and the visual display of these goods." In a compromise setting, Simonson and Nowlis (2000) found that people with a high need for uniqueness generally prefer an extreme rather than a middle option, resulting in a weaker compromise effect for people with a high, rather than low, need for uniqueness. We can infer that choosing an extreme option in a compromise setting is related to satisfying the need for uniqueness.

The other motivation, conformity, relates to the tendency to follow the group norm or expectation (Burnkrant and Cousineau 1975; Griskevicius et al 2006; Lascu and Zinkhan 1999; Venkatesan 1966). Nail (1986) suggests that the notions of uniqueness and conformity are opposite concepts, in that uniqueness is labeled anti-conformity. Simonson and his colleague (Simonson 1989; Simonson and Tversky 1992) found that when people anticipate having to justify their choice there is a greater tendency to prefer a middle option - to conform - rather than an extreme option, because it results in less criticism by others, thus amplifying the compromise effect. 
Prior research has explored how people manage, or balance, conflicting motivations, in this case the desire to be unique versus that to conform (Berger and Heath 2007, 2008; Brewer 1991; Chan, Berger, and Van Boven 2012; Cialdini and Goldstein 2004; Herpen, Pieters, and Zeelenberg 2014; Hornsey and Jetten 2004; Gierl and Huettl 2010). Brewer (1991, p. 477) advances optimal distinctiveness theory: "Social identity derives from a fundamental tension between human needs for validation and similarity to others and a countervailing need for uniqueness and individuation." To share just one representative study, Chan, Berger, and Van Boven (2012) show that people can satisfy two motivations simultaneously by choosing a core brand to conform with their identity, but a different colored option to show their uniqueness.

A conclusion reached by several researchers is that when a decision-maker is faced with conflicting motivations, a means to manage the situation is that when one motivation is satisfied, the drive toward that motivation diminishes so they instead pursue the other motivation that has yet to be satisfied (Fishbach and Dhar 2004; Laran and Janiszewski 2009; Chan, Berger, and Van Boven 2012). When this logic is applied within a compromise effect setting, we argue that when all the option-related information is displayed in black-on-white, balancing these motivations is more difficult relative to the situation where the option-related product information is presented in unique colors. In the latter case any choice automatically has some effect on satisfying uniqueness - the product-related information is unique irrespective of the brand's location in the choice set - thus making it easier to conform by choosing the middle option. Even those with a high need for uniqueness can therefore partially satisfy their desire to be unique even if they chose the middle option; thus, using unique colors can counteract the general tendency for those with high need for uniqueness to choose an extreme option (Simonson and Nowlis, 2000). The assumption that choosing different colored options could satisfy one's uniqueness has been supported by Chan, Berger, 
and Van Boven (2012), but in their case the color was inherent to the product. What we propose is subtle: the color of the font affects choices.

When all information is presented in black-on-white managing these conflicting motivations simultaneously is more difficult: a means to satisfy uniqueness by choosing a unique colored font is no longer available. Thus, we expect differences in choice behavior when option-related information is displayed in unique colors relative to black-on-white, holding the choice set constant. Given that any choice in a unique-color-context will at least partially satisfy the decision-maker's need for uniqueness, this leaves the desire to satisfy the conformity motivation unmet. Consequently, decision-makers will have a greater tendency to choose the middle option than will those in the black-on-white condition, as this option will better satisfy both motivational drives.

A second, entirely different, theoretical explanation could also explain a stronger compromise effect under the color condition. Varying color could increase encoding difficulty for participants, a cognitive resource based view. In a study on the persuasiveness of advertisements, Meyers-Levy and Peracchio (1995) found that processing colored advertisement information requires greater cognitive resources than does processing blackand-white; thus, if resources dedicated to processing the advertisement are insufficient, then black-and-white advertisements are more persuasive. Applying this insight in a compromise effect setting, people under the color condition may not process information deeply enough to make a systematic decision, in which case decision-makers will resort to a simplifying choice heuristic (Payne, Bettman, and Johnson 1993). In this case, that would mean choosing the middle option, resulting in a greater compromise effect. In sum, both consumer motivation theory and the cognitive resource based theory predict a stronger compromise effect under the color condition relative to the black-on-white condition. Both these theoretical arguments lead to the main research hypothesis: 
H1: The compromise effect will be greater if brand related information is presented in unique colors compared to all brands using black-on-white font.

\section{Where to from here?}

We first present findings from a USA-based survey that lends credence to the iPhone sales patterns observed in Korea. Studies $1 \mathrm{a}-1 \mathrm{~b}$ will then establish that the compromise effect is stronger in the different color conditions versus black-on-white condition (or all options using one color) in lab experiments across three different products. In Study 2, a mediation hypothesis is developed and tested in order to exclude the argument that choices are driven by a specific color, for example, a preference for blue. Study 2 also provides evidence in support of consumer motivation theory explaining these findings as opposed to the cognitive resource based view. Study 3 serves two purposes; first, to demonstrate that the expectation of having to justify one's decisions moderates the effect of color on decision making and, second, that using different colors to present different attributes of the products (but with all options using the same color scheme, as is often the case on B2C websites) does not affect choices, but rather has outcomes similar to black-on-white. Finally, Studies $4 \mathrm{a}-4 \mathrm{~b}$ are field studies, where the basic finding of the research is tested in a true retail setting and in a Halloween candy choice situation.

\section{CONFIRMATORY SURVEY}

One hundred and seventy-four US adults (average age $=35.8,56.9 \%$ female) from an online panel (Amazon MTurk) participated in this study. Using the MTurk screening category, only participants whose primary mobile device is an iPhone were invited to participate in the survey. Participants were asked the model of their current iPhone, the memory size, and other 
related information (such as the carrier and monthly fee). Participants were then asked to name the make of their previous mobile phone. If a participant had previously owned an iPhone, they were asked to also provide their previous iPhone's model and memory size. We excluded the participants' answers if they declared a memory size that was not available for a specific model $(n=147$ of 174$)$. After this screening, there were 294 cases remaining in the dataset.

After responding to the survey questions regarding their iPhones, all participants answered 12 further items (e.g., 'I often combine possessions in such a way that I create a personal image that cannot be duplicated') from a short-version of the NFU (need for uniqueness) scale (Ruvio, Shoham, \& Brenčič, 2008), along a 5-point scale, where $1=$ strongly disagree, $5=$ strongly agree (Cronbach's $\alpha=.94)$. Participants were categorized into two groups based on the absolute value of '3,' so 105 participants with an NFU score below 3 are categorized as low- and 69 as high-NFU.

\section{Results}

First, the overall results indicate that preference for the middle memory option is higher when the iPhone model provides four or more colored options (54.8\% (51/93) choose the middle memory size), than when only two or three basic color options are offered $(38.5 \%$ $\left.(78 / 201), x^{2}(1)=6.64, p<.05\right)$.

Second, there is an interaction with an individual's NFU, in that the pattern above is stronger for those with a high need for uniqueness, as shown in Figure 1. Specifically, the preference for the middle memory option for those with high NFU is greater when their iPhone model provides four or more colored options $(61.5 \%(24 / 39)$ chose the middle memory size) than when their iPhone model has only two or three colored options $(26.3 \%$ $\left.(29 / 80), x^{2}(1)=6.79, p<.01\right)$. This evidence suggests that if one can express their 
uniqueness through color (when there are more color options to choose from), they compromise (choose the middle option) on memory size; but given a smaller array of colors they are more likely to choose an extreme memory option. For low NFU individuals, the preference for the middle option is not influenced by the numbers of colors available $(50.0 \%$ $(27 / 54)$ vs. $\left.50.5 \%(49 / 121), x^{2}(1)=1.37, p=.24\right)$.

This results could be driven by the decision complexity, based on the number of colors/options rather than by the uniqueness of expression gained by choosing a unique color option. This alternative explanation is possible, since other researchers suggest that people, under the relatively complex [vs. simple] decision situation, might more frequently choose the middle option (e.g., Dhar, Nowlis, and Sherman, 2000; Kim, 2017). However, the significant effect of NFU in this study does empirically support our original theorizing and, in addition, we will use subsequently use more control in the experiments that follow, in order to definitively exclude this alternative explanation.

\section{INSERT FIGURE 1 ABOUT HERE}

These results give us confidence on two counts. First, the phenomenon observed in South Korea is not unique to that country, but also exists in the United States. Second, the survey offers some preliminary support for the idea that selection of a colored option goes some way to satisfy an individual's need for uniqueness, hence the tendency to conform on other characteristics, in this case memory size.

\section{STUDIES 1A-B: THE EFFECT OF COLOR ON THE COMPROMISE EFFECT - EVIDENCE FROM LAB EXPERIMENTS}

\section{Study 1A}


Subjects and Design. Study 1A empirically tests the impact of using unique colors versus black-on-white on the magnitude of the compromise effect. One hundred and fifty-six adults $(52.6 \%$ female, average age $=35.89)$ from an online panel (Amazon MTurk) participated in the study. Participants were randomly assigned to one of 2 (choice set: points $\mathrm{ABC}$ vs. points $\mathrm{BCD}) \mathrm{X} 2$ (color of information presentation: black-on-white vs. color) between-subject experimental conditions.

Participants were first asked to choose between options concerning either a computer or a box of chocolates. The attribute information was modified from Larson and Billeter (2013) and Kim and Kim (2016). The computer options vary in terms of speed and graphics card while the boxes of chocolate differ in terms of taste rating and number of flavors. Each participant was asked to choose a computer first and then to choose a box of chocolates. Product-related information is manipulated by using either black-on-white font or color font, as shown in Figure 2. Finally, participants were debriefed and thanked for their participation.

\section{INSERT FIGURE 2 ABOUT HERE}

Results. The compromise effect is calculated as the difference in the relative share of Option B out of Options B and C (i.e., probability $\{\mathrm{B} ; \mathrm{B}, \mathrm{C}\})$ in the $\mathrm{ABC}$ condition, compared to the BCD condition (Chernev 2004). Therefore, participants who choose option A in the $\mathrm{ABC}$ condition and option $\mathrm{D}$ in the $\mathrm{BCD}$ condition were excluded from further analysis (this left 124 responses for computers and 105 for the boxes of chocolate). Separate analyses were conducted for the computers and boxes of chocolates. This replicates Kim and Kim's (2016) study, in that the compromise effect should be stronger for the utilitarian computer product and weaker for the hedonic box of chocolates; however, in their study all stimuli were blackon-white. Their argument for differences in the magnitude of the compromise effect was 
attributable to different forms of decision-making: utilitarian decisions are more cognitively driven whereas hedonic product preferences are more emotionally driven. For our purposes, we are interested in the relative levels of the respective compromise effects between black-onwhite and color, not the absolute levels.

Consistent with expectations, the compromise effect is significant for the computer, as the relative share of computer $\mathrm{B}$ (out of computers $\mathrm{B}$ and $\mathrm{C}$ ) under the $\mathrm{ABC}$ condition is $69.6 \%$ (48/69) versus $34.5 \%$ (19/55) in the BCD condition; thus the compromise effect equals $35.1 \%$ $\left(x^{2}(1)=15.11, p<.001\right)$. On the other hand, the compromise effect is not significant for the box of chocolates (chocolate box B's share under the ABC versus BCD condition $=70.7 \%$ $(29 / 41)$ against $73.4 \%(47 / 64)$; thus the compromise effect $=-2.7 \%\left(\mathcal{X}^{2}(1)=.09, p>.10\right)$.

To test H1, binary logistic regression models were run for each product where brand choice is the dependent variable $(1=$ choosing option $\mathrm{B}, 0=$ choosing option $\mathrm{C})$ and choice set ( $\mathrm{ABC}$ vs. $\mathrm{BCD})$, color of information presentation (black-on-white vs. color), and the interaction effect for each product are the independent variables. Consistent with expectations, there is a significant interaction effect between the two factors (computer: Wald $=2.73, p$ $<.10$, box of chocolates: Wald $=5.20, p<.05)$ for each product. As shown in Table 1 , for computer products the compromise effect is not significant under the black-and-white condition (computer B's share under the ABC vs. BCD condition $=61.8 \%(21 / 34)$ vs. $41.7 \%$ $(10 / 24)$; compromise effect $=20.1 \%\left(\mathcal{X}^{2}(1)=2.28, p>.10\right)$. However, the compromise effect is significantly positive under the color condition (computer B's share under the ABC vs. BCD condition $=77.1 \%(27 / 35)$ vs. $29.0 \%(9 / 31)$; compromise effect $=48.1 \%\left(\chi^{2}(1)=15.35\right.$, $p<.001)$. A similar pattern is found for the boxes of chocolate. The compromise effect under the black-on-white condition is significant and negative (the chocolate box B's share under the $\mathrm{ABC}$ condition $=64.7 \%(11 / 17)$ vs. $89.7 \%(26 / 29)$ in the $\mathrm{BCD}$ condition; the compromise effect $=-25.0 \%\left(x^{2}(1)=4.24, p<.05\right)$. However, the compromise effect under the color 
condition is directional but not significant (the chocolate box B's share under the ABC condition $=75.0 \%(18 / 24)$ vs. $60.0 \%(21 / 35)$ in the BCD condition; the compromise effect $=$ $+15.0 \%\left(x^{2}(1)=1.43, p>.10\right)$. Although the compromise effect is not significant, choices shifted substantially toward realizing a compromise effect relative to the black-on-white condition. Therefore, the results suggest that choosing the compromise option is greater under the color condition rather than under the black-on-white condition regardless of the type of product, consistent with H1. This was true for both the utilitarian computer and for the hedonic box of chocolates. However, a limitation of this study is that participants were asked to conduct two different tasks sequentially. Thus, there is a possibility that the first choice influenced the selection of the second choice, which could occur if the decision rule used in the first choice was then applied to the second choice (Drolet 2002) - although given the differences in the absolute levels of the compromise effects, this seems unlikely. In Study $1 b$ participants were only asked to make one decision.

\section{INSERT TABLE 1 ABOUT HERE}

\section{Study 1B}

In the previous study, we compared using unique colored fonts to black-and-white. If our original theorizing (i.e., the role of unique motivation in choice) is right, we should find a similar effect when we compare the different color condition with the same color condition. Put differently, the compromise effect is expected to be stronger under different (vs. same) color conditions because people find it relatively more difficult to express their uniqueness when they choose one option from a set of same color options, no matter what the color is. We also used actual stimuli from Amazon.com in order to enhance external validity. 
Eighty-eight US adults $(56.8 \%$ female, average age $=33.88)$ from an online panel (Amazon MTurk) participated in the study. Participants were randomly assigned to one of 2 (color of information presentation: same color (i.e., all options presented in blue) vs. different color (i.e., options presented in red, blue and green)) between-subjects experimental conditions. The cameras are different mainly in terms of brand, price and resolution attribute. The color of information presentation is also manipulated in a different way, by either displaying the product pictures and attributes all in blue or in different colors, as shown in Figure 3. However, the middle range product is the same color, blue, across both experimental conditions. Participants were asked to show their general attitude toward three brands (Cannon, Sony, and Samsung) as well as the general attitude toward the color, along a 7-point scale $(1=$ do not like, $7=$ like very much $)$.

\section{INSERT FIGURE 3 ABOUT HERE}

The results are similar to Study $1 \mathrm{~A}$ in that the percentage of participants choosing the middle option is higher under the different color condition $(40.0 \%(18 / 45))$ than under the same color condition $\left(19.0 \%(8 / 42), \chi^{2}(1)=4.55, p<.05\right)$. Further analysis suggests that this effect is significant after controlling for the attitude toward different brands. Specifically, the attitude toward Sony brand significantly influences the option choice (Wald $=5.13, p<.05$ ), whereas the color of information is still significant in a binary logistic regression $($ Wald $=$ $4.64, p<.05$ ). In addition, attitude toward the color blue was even higher for the same (vs. different $)$ color condition $\left(\mathrm{M}_{\text {same_color }}=6.16\right.$ vs. $\left.\mathrm{M}_{\text {different_color }}=5.67, F(1,86)=4.16, p<.05\right)$. Therefore, a strong compromise effect could not be explained by the preference for the specific color. In sum, we replicated the results of the Study 1A that used stylized stimuli using real retail advertising stimuli. 


\section{STUDY 2: TESTING AN UNDERLYING MECHANISM DRIVING THE COMPROMISE EFFECT}

The purpose of Study 2 is to test an underlying mechanism that can explain a stronger compromise effect under a color condition rather than a black-on-white or same color format. Two plausible explanations have been proffered. The first, a motivation-based perspective, stems from the idea that the colored information could offer the decision-maker an opportunity to partially satiate their desire to express uniqueness regardless of their choice outcome - each option's product-related information is associated with its own unique color. Because people under the color condition can satisfy their uniqueness motivation with any alternative they are more likely to choose the middle option relative to those seeing black-onwhite only in order to satisfy their conformity motivation, resulting in a stronger compromise effect. The rival, resource-based perspective stems from the possibility that colored information is more difficult to encode, hence decision makers may resort to simplifying heuristics. An obvious heuristic is the compromise effect - the automatic reaction is to select the middle of three options presented.

To ascertain which of these competing mechanisms is driving choice behavior we measure decision-time, the perceived difficulty of encoding the product information, the recognition of product information, and the perceived revealed uniqueness of the respondents' choice. If participants spend more time on decisions, or experience a higher perceived level of difficulty in encoding the product information when the stimuli are in color versus black-onwhite, then the resource-based theory best explains the results. On the other hand, if there is no perceived difference in the difficulty of processing, and a stronger compromise effect is 
evident under the color rather than the black-on-white information situation, then the motivation-based theory offers the best explanation.

In addition to these measures, this study differs from Study 1A in two ways. In Study 2 participants make only one decision, not two. The second difference is that colors are systematically rotated so that we can rule-out the explanation that choices were affected by a preference for a specific color. In Study 1B blue was always the middle option, which only occurred approximately one third of the time in the color conditions of this study.

\section{Subjects and Design}

Two hundred and fifty-eight adults $(41.1 \%$ female, average age $=34.6)$ from the Amazon MTurk online panel participated in the study. Participants were randomly assigned to one of 2 (choice set: $\mathrm{ABC}$ vs. BCD) X 4 (color of information presentation: black-on-white vs. color I (options presented in blue, green, then red) vs. color II (green, red, and then blue) vs. color III (red, blue, and then green)) X 2 (product type: computer vs. box of chocolate) between-subjects experimental conditions. It is anticipated that there will not be a significant effect due to the order of the color, so that ultimately color conditions I - III can be amalgamated. More responses to the black-on-white condition were therefore collected relative to colors I - III.

The target products are the same as in Study 1A. After choosing, participants were asked to respond to two questions concerning the perceived difficulty of encoding the product information, using a 7-point Likert scale ("The information presented was very confusing" and "It was very difficult for me to make sense of the information;" $1=$ strongly disagree, $7=$ strongly agree, Cronbach' $\alpha=.86$ ) and the perceived revealed uniqueness ("My selection did show my uniqueness very much" and "My selection did show my distinctive image very much;" $1=$ strongly disagree, $7=$ strongly agree, Cronbach' $\alpha=.90)$. After that, participants 
were asked to complete a two-alternative forced choice recognition task. Roughly half of the participants were shown one of the options that they had seen during the previous choice task, whereas the remaining participants were exposed to an option that they had not seen previously. Participants had to respond 'yes' or 'no' to indicate whether they had seen the option before. Finally, they were debriefed and thanked for their participation.

\section{Results}

Choice results. Eighteen participants (7\%) were excluded from further analysis because of the time they spent on the choice task although, in fact, their inclusion makes little difference. Fourteen of the 18 took less than four seconds, and four took longer than 100 seconds to reach a decision. The remaining responses therefore number 240 .

The first step was to determine if the three color conditions can be amalgamated. A binary logistic regression was therefore run with those who chose either option $\mathrm{B}$ or $\mathrm{C}$, the dependent variable (new $n=186$ ), and choice set $(A B C$ vs. $B C D)$ and two dummy codes to capture the three color conditions as the independent variables. As expected, there is no significant effect due to the three different color conditions (the main effects for the color conditions and the interaction effects with the choice set are not statistically significant; all $p$ 's $>$.10). We therefore collapsed the three color conditions into one, which can then be compared to the black-on-white condition in further analyses.

A second binary logistic regression analysis was then run, where choice is the dependent variable $(1=$ choosing option $\mathrm{B}, 0=$ choosing option $\mathrm{C})$ and choice set $(\mathrm{ABC}$ vs. $\mathrm{BCD}$ ), color of information presentation (black-on-white vs. color), product type (computer vs. chocolate) and their interactions are the independent variables. The results reveal a significant main effect for product type, in that the compromise effect is stronger for the utilitarian product than for the hedonic product (Wald $=8.06, p<.01$ ). Specifically, the 
compromise effect is significant for the computer (share of $\mathrm{B}$ under the $\mathrm{ABC}$ vs. $\mathrm{BCD}$ condition $=80.8 \%(42 / 52)$ vs. $24.5 \%(12 / 49)$; compromise effect $=56.3 \%, \mathcal{x}^{2}(1)=32.12, p$ $<.001)$. On the other hand, the compromise effect is not significant for the chocolates (the share of chocolate box $\mathrm{B}$ under the $\mathrm{ABC}$ vs. $\mathrm{BCD}$ condition $=82.6 \%(19 / 23)$ vs. $66.1 \%$ $(41 / 62)$; compromise effect $\left.=16.5 \%, x^{2}(1)=.14, p>.10\right)$. The interaction effects with product type are not significant $(p>.10)$

More importantly, the interaction between choice set and color of information presentation is marginally significant (Wald $=3.26, p=.07$ ). We found a marginally significant compromise effect under the black-on-white condition (option B share under the $\mathrm{ABC}$ option condition vs. $\mathrm{BCD}$ option condition $=71.9 \%(23 / 32)$ vs. $50.0 \%(20 / 40)$; the compromise effect $\left.=21.9 \%, x^{2}(1)=3.54, p<.10\right)$. However, there is a stronger significant compromise effect under the color condition (option B share under the ABC option condition vs. $\mathrm{BCD}$ option condition $=88.4 \%(38 / 43)$ vs. $46.5 \%(33 / 71)$; the compromise effect $=41.9 \%$, $\left.x^{2}(1)=20.01, p<.001\right)$. The same pattern is found for the different products as well, as shown in Table 2. The results therefore suggest that the compromise effect is higher under the color condition than the black-on-white condition.

\section{INSERT TABLE 2 ABOUT HERE}

Mediation Analysis. The time spent decision-making is not statistically different between the color and black-on-white conditions $\left(\mathrm{M}_{\text {color }}=17.39\right.$ seconds vs. $\mathrm{M}_{\mathrm{b} \& \mathrm{w}}=18.75$ seconds; $F(1,237)=.73, p>.10)$. In addition, the perceived difficulty of encoding the product information is not significantly different across the two conditions $\left(\mathrm{M}_{\text {color }}=2.00 \mathrm{vs}\right.$. $\left.\mathrm{M}_{\mathrm{b} \& \mathrm{w}}=1.91 ; F(1,237)=.27, p>.10\right)$. Finally, product recognition is also no different across the two conditions (correct percentage: $\mathrm{M}_{\text {color }}=89.7 \%$ vs. $\mathrm{M}_{\mathrm{b} \& \mathrm{w}}=88.2 \%, x^{2}(1)=.71, p>.10$ ). 
On the other hand, the perceived revealed uniqueness is significantly different across the color conditions. Participants rated the perceived revealed uniqueness higher under the color condition $\left(\mathrm{M}_{\text {color }}=3.79\right)$ than under the black-on-white condition $\left(\mathrm{M}_{\mathrm{b} \& \mathrm{w}}=3.33, F(1,237)=\right.$ $4.23, p<.05)$. Thus, those in the color condition were more prone to choose the compromise option, yet they perceived their choice as more unique.

As a further check, to verify if perceived revealed uniqueness has a significant mediating role on the compromise effect, a multiple mediation analysis based on Preacher and Hayes (2008) was conducted. Preacher and Hayes' SPSS macro modules with 5,000 bootstrapped samples was used. Like Chernev (2004) and Larson and Billeter (2014), the preference for the middle option versus the extreme option out of three options is treated as the dependent variable. The independent variable is the color of information presentation (black-on-white vs. color), and the three mediators are the perceived difficulty of encoding the product information, the perceived revealed uniqueness, and the time spent during decision. The moderator is product type. The results show a significant indirect effect only for perceived revealed uniqueness (95\% bootstrap confidence interval (CI): -.280, -.005). Neither the perceived difficulty of encoding the product information nor the time spent making the decision are significant (95\% CI: -.061, .145 for perceived difficulty and 95\% CI: -.117, .025 for time spent).

The mediation analyses therefore show a significant mediating role for perceived revealed uniqueness revealing a stronger compromise effect under the color condition relative to the black-on-white condition, which is consistent with the argument that individuals try to balance the motivations for uniqueness and conformity. These findings do not lend support for a resource-based perspective. Thus, studies $1 \mathrm{~A}-\mathrm{B}$ and 2 provide support for $\mathrm{H} 1$; the compromise effect is stronger under a color information presentation than black-on-white. 


\section{STUDY 3: TESTING THE MODERATING EFFECT OF ACCUNTABILITY FOR COLOR EFFECT}

In Study 3 empirical evidence is provided concerning the role of conformity versus uniqueness by introducing a moderator; decision makers will make their choice either under an expectation of having to justify their choice or thinking their choice is made in confidence. Simonson and his colleague (Simonson 1989; Simonson and Tversky 1992) suggest that people under a high accountability condition show a higher compromise effect due to the ease with which a conforming, middle option can be justified. Put differently, people in a high accountability situation are likely to put more weight on the need to conform rather than on the uniqueness motivation. Following this line of thought, we predict that under high accountability participants will show a high compromise effect regardless of whether the information is presented in color or black-on-white. On the other hand, people under a lowaccountability condition will show the same pattern of selection shown in Studies 1 and 2, so that the compromise effect is higher in the color condition than the black-on-white condition.

In addition, in this study another boundary condition for the color effect is tested. As noted at the beginning of this manuscript, firms such as Amazon and TripAdvisor use multiple font colors when presenting options to customers, but the same combination of colors is used for each option. We therefore compare each option having its own unique color, as in studies 1 and 2, to each option being presented in a mix of font colors, but the mix is constant across the options. This is broadly analogous to pages a buyer might see on Amazon.com (see Figure 4). Evidence thus far supports our view that choosing any option from a choice set featuring different colored options partially satisfies people's uniqueness motivation, thus amplifying the compromise effect; however, this uniqueness element would be lost if each option used the same combination of colors. Thus, a set combination of colors 
across all options is expected to result in choice behavior more consistent with the black-onwhite condition than the unique color font condition.

\section{INSERT FIGURE 4 ABOUT HERE}

\section{Subjects and Design}

Two hundred and fifty-five adults $(41.6 \%$ female, average age $=34.3)$ from the online Amazon MTurk panel participated in the study. Participants were randomly assigned to one of 2 (choice set: $\mathrm{ABC}$ vs. $\mathrm{BCD}$ ) X 3 (color of information presentation: black-on-white versus Color I (where each option is presented in a unique color, as in studies 1 and 2) versus Color II (where the attributes of the options are in different colors, but the combination of colors across options is the same) X 2 (level of accountability: high vs. low) between-subjects conditions.

The target product is boxes of chocolate, as in Studies 1A and 2. The level of accountability is manipulated using the method proposed by Simonson (1989). Specifically, participants in the high accountability condition were informed that their decision would be evaluated by others and they might be asked to justify their decision. They were asked to print their first name on the response document. Alternatively, participants in the low accountability were informed that their choice remained confidential. After that, participants were asked to choose one option from the three alternatives. Participants were randomly assigned to one of the three color conditions, as illustrated in Figure 4. After making their choice, as a manipulation check, participants answered two accountability-related questions ("I anticipated that I would be asked to justify my choices to the others" and "I anticipated that my choices would be evaluated by others"; $1=$ strongly disagree, $7=$ strongly agree, Cronbach' $\alpha=.83$ ). Finally, they were debriefed and thanked for their participation. 


\section{Results}

Manipulation check. As expected, the mean for the manipulation check measures is significantly higher under the high-accountability condition than under the low-accountability condition $\left(\mathrm{M}_{-}\right.$high Accountability $=4.32$ vs. $\mathrm{M}_{-}$low Accountability $\left.=3.85, F(1,249)=4.66, p<.05\right)$. However, there is no significant difference due to the accountability manipulation across the three color conditions $(F(2,249)=1.63, p>.10)$.

Choice results. The results confirm our expectations in that the effect of color on the compromise effect is only realized if each option uses a different color, but not if a consistent set of colors is applied to each option (Table 3). Further, in the low accountability condition we replicate the findings from the previous studies in that the compromise effect is only significant for the Color I condition (option B under the ABC vs. BCD condition $=100 \%$ $(10 / 10)$ vs. $64.7 \%(11 / 17)$; the compromise effect $\left.=35.3 \%, x^{2}(1)=4.54, p<.05\right)$. The compromise effect is not significant for the black-on-white condition (B's share under the $\mathrm{ABC}$ vs. $\mathrm{BCD}$ condition $=58.3 \%(7 / 12)$ vs. $60.9 \%(14 / 23)$; the compromise effect $=-2.5 \%$, $\mathcal{X}^{2}(1)=.15, p>.10$ ) or the Color II condition (B's share under the ABC vs. BCD condition $=$ $78.6 \%(11 / 14)$ vs. $72.7 \%(16 / 22)$; the compromise effect $\left.=5.8 \%, \chi^{2}(1)=.16, p>.10\right)$.

In contrast, there is a significant compromise effect in the high accountability condition regardless of the color of information presentation. For the black-on-white condition (option B's share under the ABC vs. BCD option condition $=100.0 \%(19 / 19)$ vs $66.7 \%(14 / 21)$; the compromise effect $\left.=33.3 \%, x^{2}(1)=7.68, p<.01\right)$, for the Color $\mathrm{I}$ condition (B's share under the ABC vs. BCD condition $=100 \%(9 / 9)$ vs. $61.9 \%(13 / 21)$; the compromise effect $\left.=38.1 \%, x^{2}(1)=4.68, p<.05\right)$, and the Color II condition (B's share 
under the $\mathrm{ABC}$ vs. $\mathrm{BCD}$ condition $=100 \%(11 / 11)$ vs. $70.0 \%(14 / 20)$; compromise effect $=$ $\left.30.0 \%, x^{2}(1)=4.01, p<.05\right)$

\section{INSERT TABLE 4 ABOUT HERE}

Thus, as anticipated, the expectation of having to justify one's decisions moderates the color effect found in studies 1 and 2. Further, evidence for the uniqueness motivation mounts. If each option appears in a unique color, a strong compromise effect is realized. But color alone does not explain the findings. If the attributes of the options are presented in different colors but each option uses the same combination of colors - as is often the case on $\mathrm{B} 2 \mathrm{C}$ websites - choices are broadly similar to choices in the black-on-white condition.

\section{STUDY 4A: SUSHI SALES FIELD STUDY}

\section{Materials and Methods}

A field study was conducted in a Japanese sushi store in Auckland, New Zealand during May, 2017. The restaurant is located on a main street located in the business and commercial area. The main customer groups of the restaurant are businesspeople, students and staff from a nearby university. The restaurant provides a pick-your-own sushi menu and Japanese take-away dishes. The store provides around 30 different types of pick-your-own sushi and tempura, with a price range from $\$ 1.00$ to $\$ 3.00$. We focused on the 10 best-selling sushi pieces that range in price from $\$ 1.00$ to $\$ 1.20$, which mitigates the effect that price may have on choice.

With the cooperation of the owner and manager of the store, we systematically manipulated the background color of the sushi display, as shown in Figure 5. The experiment 
was conducted over three working days, Tuesday, Wednesday and Thursday. During the three days the sushi variety was not changed. We manipulated the colored display by inserting four different colored paper strips on the bottom of display table, under the sushi, on the middle day, Wednesday, but left the standard display (a woodgrain plastic) in place on the surrounding days.

\section{INSERT FIGURE 5 ABOUT HERE}

\section{Results and Discussion}

We collected the sales record around 3:00pm each day in order to insure all focal pieces were available. Sales quantities swing daily, hence the store does not make additional sushi after 3:00pm because sushi are made in large rolls of 10 pieces. Our focus is on comparative sales of two items of sushi located at the ends of the cabinet display, in the extreme positions: a salmon avocado on the left and a mini sushi roll on the right side, with eight alternative choices in between. The 10 sushi are different (e.g., salmon, tuna, chicken); nevertheless, we consider selecting the extreme options as expressing more uniqueness in choice compared with choosing one of the eight middle 'conforming' options.

A total 171, 148, and 201 pieces of sushi were sold for Tuesday (the control condition), Wednesday (the experimental condition), and Thursday (the control condition), as shown in Table 4. The sale of the mini sushi was not different across different days; 6.4\% (11/171) for Tuesday, versus $6.1 \%(9 / 148)$ for Wednesday, and 5.5\% (11/201) for Thursday; $\chi^{2}(2)=.16, p$ >.10). However, the sale of salmon avocado was significantly different over the three days, with $27.5 \%$ (47/171) selling on Tuesday versus $11.5 \%$ (17/148) on Wednesday, and 26.9\% $(54 / 201)$ on Thursday; $\left.x^{2}(2)=14.83, p<.001\right)$. Specifically, the sale of this sushi was higher in the control conditions $(27.2 \%(101 / 372))$ than in the colored display condition $(11.5 \%$ $\left.(17 / 148), x^{2}(1)=14.81, p<.001\right)$. Furthermore, the sale of the eight sushi types located in the 
middle rows was higher in the colored condition $(82.4 \%(122 / 148))$ than in the two control conditions $\left(66.9 \%(249 / 372), x^{2}(1)=12.44, p<.001\right)$. Thus, even in the open retail atmosphere of a busy city food shop, the options in the middle location are selected more frequently by customers when the background is colored.

\section{INSERT TABLE 4 ABOUT HERE}

\section{STUDY 4B: HALLOWEEN CANDY CHOICE FIELD STUDY}

\section{Materials and Methods}

As in many countries, Halloween rituals were observed in one author's country on October 31,2017 . In the early evening many children - appropriately disguised in various horrific manifestations - visited the author's home in the hope of receiving a treat. On this occasion, though, instead of receiving compliments on their costume and some candy, 99 of the children (with their guardian's permission) were asked to pick a candy from one of three plastic boxes. The mixed-gender sample was approximately aged 6yrs to $12 \mathrm{yrs}$.

Unbeknownst to the trick-or-treaters, they were presented one of two sets of three plastic boxes filled with candy (see Figure 6). In one set, the three plastic boxes were wrapped in plain white wrapper (i.e., black-on-white condition), and in the other set the three boxes were wrapped in red, yellow and blue (colored condition). Each carton was clearly labelled with black letters of "LESS SOUR candy," "SOUR candy" or "VERY SOUR candy", thus endeavoring to unambiguously display a single monotonic product related attribute. The order of the different sourness levels was not rotated in that the SOUR candy was always located in the middle position. Children were randomly assigned to the different color conditions. Each child was asked to approach the table and to choose a candy from one of the 
three boxes. The process was explained to the adults which evoked considerable interest and no ire whatsoever.

\section{INSERT FIGURE 6 ABOUT HERE}

\section{Results}

When asked to take a candy from the plain white boxes, 13 of the 51 children (25.5\%) chose the middle, "sour" option. On the other hand, when offered the candy in the colored boxes, 21 of the 48 children (43.8\%) selected the middle option. A chi-square test reveals these proportions to be significantly different $\left(\chi^{2}(1)=3.66, p=.056\right)$. Thus, consistent with the laboratory studies, presenting options in unique colors - a characteristic that is entirely independent of a product's performance - affects choices. Color, whether fonts, backgrounds or containers, appears to partially satiate one's uniqueness motivation, thus increasing the proclivity to choose the middle, conforming option.

\section{GENERAL DISCUSSION}

This series of experiments has added to our understanding of an underlying mechanism driving the compromise effect, notably the internal desire to balance uniqueness versus conformity. Studies $1 \mathrm{~A}$ and $1 \mathrm{~B}$ provided laboratory evidence to confirm the field observation that color itself can change the choice results significantly. Notably, presenting options in unique colors amplifies the compromise effect - choosing the middle option. Study 2 confirms the role of the interplay of the needs for uniqueness and conformity as important motivators behind this outcome. Those in the color condition exhibited a stronger compromise effect, as anticipated, yet they rated their preferences as more unique than did those in the black-on-white condition. Importantly, the resource-based view was ruled-out as 
a possible explanation for these findings: neither the time taken to complete the task nor the perceived level of encoding difficulty differed across the conditions.

Study 3 tested the moderating effect of accountability on the impact of color on the compromise effect. The effect of color was only realized in the low accountability condition, consistent with expectations; in the high accountability condition a compromise effect was realized regardless of font color, a finding consistent with prior studies using black-on-white stimuli. Along the way the notion that color alone creates an effect has been addressed by altering the color of the attribute descriptions but keeping the color scheme constant across options versus presenting each option's product-related information in a unique color. The greater compromise effect was only realized if each option's product related information is presented in a unique color. Considering that some of the major on-line retailers such Amazon.com and TripAdvisor.com often present options in combinations of colors but each option is presented in an identical color scheme, this insight has clear practical import. The evidence herein supports our supposition that presenting each option in a unique color partially satiates people's need for uniqueness, thus amplifies the need to conform, hence the greater tendency to choose the middle option. Presenting attribute information in a consistent color scheme is, for all intents and purposes, no different than presenting all option related information in black-on-white.

The first field study takes the conclusions of the controlled laboratory experiments and tests them in a retail environment. The sushi shop environment makes an ideal testing ground, as it is small enough to allow some control and yet sales of individual items are large enough to provide statistical testing of sales levels under different conditions (solid background versus colored background) and busy enough to provide a good test of the robustness of a color induced compromise effect. Consistent with the previous findings, there was a greater tendency to choose middle options in the colored background condition. Similarly, the 
Halloween candy study also demonstrates that when asked to select a candy from one of three white plastic boxes versus three different colored boxes (in both cases, the contents were similar and clearly labelled in black font), there is a greater tendency to choose from the middle box when in the color condition.

\section{Theoretical Contribution}

This research effort extends our understanding of factors affecting the compromise effect several ways. First, by extending our understanding of the role of color in consumer decision-making. Prior research addressing color-related effects has focused on associations with and reactions to specific colors (c.f., Bagchi and Cheema, 2013; Bellizzi and Hite, 1992; Kress and Van Leeuwen, 2002; Labrecque and Milne, 2012). In contrast, we offer a different perspective regarding the effect of color in that it can serve to balance the competing motivations of uniqueness and conformity. Presenting option-related product information in unique colors - a characteristic independent of the options' actual performance characteristics - serves to partially satisfy the consumers' uniqueness motivation, resulting in a higher compromise effect under the color versus black-on-white condition. In Study 3, we ruled-out a resource-based explanation that the colored information requires greater cognitive resources to encode (Myers-Levey and Peracchio, 1995) and, instead, find perceptions of uniqueness mediate choices. In Study 3 we show that the color effect only applies if each option is presented in a unique color rather than the options all using a consistent but multi-colored format to present attribute related information, as is often done in the $\mathrm{B} 2 \mathrm{C}$ marketplace.

Second, this paper sheds further insight into boundary conditions relevant to the compromise effect. Even though it is common for consumers to be exposed to colored information when making choices, most compromise effect related studies use a black-onwhite presentation format. Frederick et al. (2014) have challenged the appropriateness and 
resultant insights of using such stylized formats by demonstrating that the attraction effect was attenuated when respondents made choices from sets involving a mix of colored illustrations (e.g., an image of a hotel room) along with attribute information. They argue that is it harder to compare attributes given such real-life stimuli, thus the inferior option no longer stands out. But in their studies the images themselves did not differ in color. With the exception of Study 1B that used real-life color images of the options (albeit product colors were consistent with the font), what was manipulated in this research was the color of the attribute-related information or the color of the background, as in the sushi sales field study. Study 2 ruled-out the argument that it is the color per se that affects choices, but rather the mere presence of using unique colors rather than black-on-white; or using a consistent color scheme across alternatives (Study 3). The expectation of having to justify one's decisions (Study 3) moderates the color effect, amplifying the compromise effect regardless of whether product information is presented in color or black-on-white.

Third, Lee et al. (2014) provide empirical evidence that black-on-white images are processed at a higher level of construal than are color images. Coupling this insight with that of Khan et al. (2011), that high levels of construal diminish the compromise effect, leads to the same conclusion as ours: those in the color condition will exhibit a stronger compromise effect. But, the causal mechanism proposed is different. Khan et al. (2011) argue that high construal levels reduce the tendency to make attribute level trade-offs. We do not deny this possible route, but Study 2 found there is no difference due to color with respect to encoding difficulty or in the respondents' ability to recognize product-related information post-choice; but color does affect participants' perceptions of the uniqueness of their choice. Furthermore, Study 3 shows that using a mixed, but consistent, color scheme does not amplify the compromise effect and is little different to using black-on-white. 
Fourth, Maimaran and Simonson (2011) found that self- versus other-expression influences preferences for conventional versus unconventional options, including the extreme option over the middle option. Both Maimaran and Simonson (2011) and our research acknowledge the conflicting desires to be unique and to conform; indeed, they comment that "the need to conform and the need to assert one's independence and distinctiveness are considered some of the basic motivations consumers have ...” (p. 756). However, our research differs from theirs in the following way. Maimaran and Simonson (2011, Study 1) primed self- versus other-expression, whereas our participants were not primed. Rather, the argument we advance, and support across the various studies, is that presenting each option's product descriptions in unique colors of itself serves to partially satiate the need for uniqueness, thus increasing the likelihood of choosing the compromise option. Study 2 specifically measured perceptions of uniqueness of respondents' choices, which were found to mediate the causal relationship between color manipulation and final choice. Despite those in the color condition exhibiting a greater proclivity to choose the compromise option, they rated their choice as more unique than did those in the black-on-white condition.

Finally, someone could argue that color is additional information to the choice task, thus making the decision more complex which in turn may encourage the use of a simplifying choice heuristic, like choosing the middle option (Schwarz 2004). However, this alternative explanation is not persuasive in terms of theoretical and empirical evidence. Breitmeyer, Ogmen, and Chen (2004) argue that people process an object's color at a relatively early stage, before processing other information. Indirectly, this supports our thesis that color subtly satiates one's desire for uniqueness. This apparently occurs quickly. Study 2 tracked the time taken to reach a decision, and there was no difference due to the color manipulation. Further, there was no difference in the perceived encoding difficulty or in product recognition. 


\section{Limitations and Future Research}

For the laboratory studies we used MTurk subjects and student subjects, thereby increasing internal validity but at the expense of limiting external validity. However, the results of both the confirmatory survey of iPhone sales and the Korean field study which used actual product sales, enhances the external validity of our findings while also overcoming an issue flagged by Frederick et al. (2014); namely the tendency for researchers to use stylized (numerical) stimuli. Unlike Frederick et al. (2014), results from our two field studies are similar to that of our lab studies. Nevertheless, in light of the practical relevance our findings have for on-line retailers such as Amazon.com, we strongly encourage further research confirming the color effect in a greater array of natural environments. We found using a consistent but mixed color scheme to present all the options' product related information, as is often evident on Amazon.com webpages, is little different than presenting all information in black-on-white; however, simply by giving a unique color to each option, choices are altered. Bagchi and Cheema (2013) provide evidence that background color affects on-line bidding behavior using eBay data, albeit they attributed their findings to the effect of specific colors, i.e., red is more arousing which leads to more aggressive bid jumps.

We conclude by acknowledging that the compromise effect has received attention by numerous scholars. We have established, though, that color itself acts as a manipulation that serves to balance the conflicting needs of uniqueness versus conformity, which are powerful underlying motivations. Presenting each option's product-related information in different colors significantly affects choices. Whether applying this insight in the real-world is in the consumers' best interests is a separate issue. If one subscribes to the view that is it appropriate to 'nudge' consumers into making 'appropriate' choices (Thaler and Sunstein, 2008), then further research and real-world application is certainly merited. 


\section{REFERENCES}

Bagchi, Rajesh and Amar Cheema (2013), "The Effect of Red Background on WillingnessTo-Pay: The Moderating Role of Selling Mechanism," Journal of Consumer Research, 39 (5), 947-60.

Bellizzi, Joseph A. and Robert E. Hite (1992), "Environmental Color, Consumer Feelings, and Purchase Likelihood," Psychology and Marketing, 9 (September), 347-63.

Berger, Jonah and Chip Heath (2007), "Where Consumers Diverge from Others: Identity Signaling and Product Domains," Journal of Consumer Research, 34 (August), 12134.

Bettman, James. R, Mary Frances Luce, and John W. Payne (1998), “Constructive Consumer Choice Processes," Journal of Consumer Research, 25 (December), 187-217.

Breitmeyer, Bruno G. Haluk Ogmen, and Jain Chen, (2004), “Unconscious Priming by Color and Form: Different Processes and Levels," Consciousness and Cognition, 13(1), 138157.

Brewer, Marilynn. B (1991), “The Social Self: On Being the Same and Different at the Same Time," Personality and Social Psychology Bulletin, 17 (October), 475-82.

Burnkrant, Robert. E and Alain Cousineau (1975), "Informational and Normative Social Influence in Buyer Behavior,” Journal of Consumer Research, 2 (December), 206-15.

Chan, Cindy, Jonah Berger, and Leaf Van Boven (2012), “Identifiable but not Identical: Combining Social Identity and Uniqueness Motives in Choice," Journal of Consumer Research, 39 (3), 561-73.

Chernev, Alexander (2004), "Extremeness aversion and attribute-balance effects in choice," Journal of Consumer Research, 31 (September), 249-63. 
Chuang Shih-Chieh, Cheng Yin-Hui, and Hsu Chun-Ting (2012), “The Influence of Suggestions of Reference Groups in the Compromise Effect," Journal of Economic Psychology, 33 (June), 554-65.

Cialdini, Robert. B and Noah J Goldstein (2004), “Social Influence: Compliance and Conformity," Annual Review of Psychology, 55 (February), 591-621.

Coyle, James. R and Esther Thorson (2001), “The Effects of Progressive Levels of Interactivity and Vividness in Web Marketing Sites," Journal of Advertising, 30 (October), 65-77.

De Bock, Tine, Pandelaere Mario, and Van Kenhove Patrick (2013), "When Colors Backfire: The Impact of Color Cues on Moral Judgment,” Journal of Consumer Psychology, 23 (July), 341-48.

Dhar, Ravi, Stephen M. Nowlis, and Steven J. Sherman (2000), “Trying Hard rr Hardly Trying: An Analysis of Context Effects in Choice," Journal of Consumer Psychology, 9(4), 189-200.

Dhar, Ravi and Itamar Simonson (2003), “The Effect of Forced Choice on Choice,” Journal of Marketing Research, 40 (May), 146-60.

Drolet, Aimee (2002), “Inherent Rule Variability in Consumer Choice: Changing Rules for Change's Sake,” Journal of Consumer Research, 29 (December), 293-305.

Elliot, Andrew J., Markus A. Maier, Arlen C. Moller, Ron Friedman, and Jörg Meinhardt (2007), “Color and Psychological Functioning: The Effect of Red on Performance Attainment,” Journal of Experimental Psychology: General, 136 (February), 154-68.

Fishbach, Ayelet, and Ravi Dhar (2005), “Goals as Excuses or Guides: The Liberating Effect of Perceived Goal Progress on Choice," Journal of Consumer Research, 32 (December), 370-77. 
Frederick, Shane, Leonard Lee, and Ernest Baskin (2014), “The Limits of Attraction,” Journal of Marketing Research, 51 (July), 487-507.

Griskevicius, Vladas, Noah J. Goldstein, Chad R. Mortensen, Robert B. Cialdini, and Douglas T. Kenrick (2006), “Going Along versus Going Alone: When Fundamental Motives Facilitate Strategic (Non) Conformity," Journal of Personality and Social Psychology, 91(August), 281-94.

Hornsey, Matthew. J and Jolanda Jetten (2004), “The Individual within the Group: Balancing the Need to Belong with the Need to be Different," Personality and Social Psychology Review, 8 (August), 248-64.

Houghton, David C., Frank R. Kardes, Anne Mathieu, and Itamar Simonson (1999), “Correction Processes in Consumer Choice,” Marketing Letters, 10 (May), 107-12. Khan, Uzma, Meng Zhu, and Ajay Kalra (2011), "When Trade-offs Matter: The Effect of Choice Construal on Context Effects," Journal of Marketing Research, 48 (February), $62-71$.

Kim, Jungkeun (2017), “The Influence of Graphical versus Numerical Information Representation Modes on the Compromise Effect," Marketing Letters, 28 (3), 397-409. Kim, Sungeun and Jungkeun Kim (2016), “The Influence of Hedonic versus Utilitarian Consumption Situations on the Compromise Effect," Marketing Letters, 27 (2), 387401.

Kim, Heejung S., and Aimee Drolet (2003), “Choice and Self-Expression: A Cultural Analysis of Variety-Seeking," Journal of Personality and Social Psychology, 85 (2), 373-82.

Kress, Gunther and Theo Van Leeuwen (2002), "Colour as a Semiotic Mode: Notes for a Grammar of Colour," Visual Communication, 1 (October), 343-68. 
Labrecque, Lauren. I and George. R Milne (2012), "Exciting Red and Competent Blue: The Importance of Color in Marketing," Journal of the Academy of Marketing Science, 40 (September), 711-27.

Laran, Juliano and Chris Janiszewski (2009), "Behavioral Consistency and Inconsistency in the Resolution of Goal Conflict," Journal of Consumer Research, 35 (April), 967-84. Larson, Jeffrey. S and Billeter Darron M (2013), "Consumer Behavior in "Equilibrium”: How Experiencing Physical Balance Increases Compromise Choice,” Journal of Marketing Research, 50 (August), 535-47.

Lascu, Dana-Nicoleta and George Zinkhan (1999), "Consumer Conformity: Review and Applications for Marketing Theory and Practice," Journal of Marketing Theory and Practice, 7 (July), 1-12.

Lee, Hyojin, Xiaoyan Deng, H. Rao Unnava, and Kentaro Fujita. (2014), “Monochrome Forests and Colorful Trees: The Effect of Black-and-White versus Color Imagery on Construal Level," Journal of Consumer Research, 41 (December), 1015-1032. Maimaran, Michal and Itamar Simonson (2011), "Multiple Routes to Self-versus OtherExpression in Consumer Choice," Journal of Marketing Research, 48 (August), 75566. and Wheeler. S Christian (2008), "Circles, Squares, and Choice: The Effect of Shape Arrays on Uniqueness and Variety Seeking," Journal of Marketing Research, 45 (December), 731-40.

Meyers-Levy, Joan and Laura A. Peracchio (1995), "Understanding the Effects of Color: How the Correspondence between Available and Required Resources Affects Attitudes," Journal of Consumer Research, 22 (September), 121-38. 
Mourali, Mehdi, Ulf Böckenholt, and Michel Laroche (2007), “Compromise and Attraction Effects under Prevention and Promotion Motivations," Journal of Consumer Research, 34 (August), 234-47.

Nail, Paul. R (1986), “Toward an Integration of Some Models and Theories of Social Response," Psychological Bulletin, 100 (September), 190-206.

Novemsky, Nathan, Ravi Dhar, Norbert Schwarz, and Itamar Simonson (2007), "Preference Fluency in Choice," Journal of Marketing Research, 44 (August), 347-56.

Nowlis, Stephen. M and Itamar Simonson (2000), "Sales Promotions and the Choice Context as Competing Influences on Consumer Decision Making," Journal of Consumer Psychology, 9 (December), 1-16.

Payne John. W, Bettman James. R, and Johnson Eric. J (1993), The Adaptive Decision Maker. Cambridge: Cambridge University Press.

Preacher, Kristopher. J and Andrew F. Hayes (2008), “Asymptotic and Resampling Strategies for Assessing and Comparing Indirect Effects in Multiple Mediator Models," Behavior Research Methods, 40 (August), 879-91.

Puccinelli, Nancy M., Rajesh Chandrashekaran, Dhruv Grewal, and Rajneesh Suri (2013), “Are Men Seduced by Red? The Effect of Red versus Black Prices on Price Perceptions," Journal of Retailing, 89 (June), 115-25.

Rosenkrans, Ginger (2009), “The Creativeness and Effectiveness of Online Interactive Rich Media Advertising," Journal of Interactive Advertising, 9 (March), 18-31.

Schwarz, Norbert (2004), "Meta-Cognitive Experiences in Consumer Judgment and Decision Making," Journal of Consumer Psychology, 14 (4), 332-48.

Simonson, Itamar (1989), "Choice Based on Reasons: The Case of Attraction and Compromise Effects,” Journal of Consumer Research, 16 (September), 158-74. 
and Amos Tversky (1992), "Choice in Context: Tradeoff Contrast and Extremeness

Aversion," Journal of Marketing Research, 29 (August), 281-95. and Nowlis Stephen. M (2000), “The Role of Explanations and Need for

Uniqueness in Consumer Decision Making: Unconventional Choices Based on

Reasons," Journal of Consumer Research, 27 (June), 49-68.

Snyder, Charles R. and Howard L. Fromkin (1977), “Abnormality as a Positive Characteristic:

The Development and Validation of a Scale Measuring Need for

Uniqueness,” Journal of Abnormal Psychology, 86 (October), 518-27.

Thaler, Richard H. and Cass R. Sunstein (2008), Nudge: Improving Decisions About Health, Wealth and Happiness, Yale University Press, CT.

Tian, Kelly Tepper, William O. Bearden, and Gary L. Hunter (2001), “Consumers' Need for Uniqueness: Scale Development and Validation,” Journal of Consumer Research, 28 (June), 50-66.

Venkatesan, Morreale (1966), "Experimental Study of Consumer Behavior Conformity and Independence," Journal of Marketing Research, 3 (November), 384-87.

Wang, Jing, Nathan Novemsky, Ravi Dhar, and Roy F. Baumeister (2010), “Trade-offs and Depletion in Choice,” Journal of Marketing Research, 47 (October), 910-19.

Wedel, Michel and Rik Pieters (2014), "The Buffer Effect: The Role of Color When Advertising Exposures Are Brief and Blurred,” Marketing Science, 34 (October), 13443. 
Table 1

\section{Study 1 A results}

Table 1a. Results for the computer products

\begin{tabular}{|c|c|c|c|c|}
\hline \multirow{2}{*}{ Options } & \multicolumn{2}{|c|}{$\begin{array}{l}\text { Black-on-white } \\
\text { information presentation }\end{array}$} & \multicolumn{2}{|c|}{$\begin{array}{c}\text { Color } \\
\text { information presentation }\end{array}$} \\
\hline & $\mathrm{ABC}$ & BCD & $\mathrm{ABC}$ & $\mathrm{BCD}$ \\
\hline A & $\begin{array}{l}5.6 \% \\
(2 / 36)\end{array}$ & & $\begin{array}{l}20.5 \% \\
(9 / 44)\end{array}$ & \\
\hline B & $\begin{array}{l}58.3 \% \\
(21 / 36)\end{array}$ & $\begin{array}{l}27.8 \% \\
(10 / 36)\end{array}$ & $\begin{array}{l}61.4 \% \\
(27 / 44)\end{array}$ & $\begin{array}{r}22.5 \% \\
(9 / 40)\end{array}$ \\
\hline $\mathbf{C}$ & $\begin{array}{l}36.1 \% \\
(13 / 36)\end{array}$ & $\begin{array}{l}38.9 \% \\
(14 / 36)\end{array}$ & $\begin{array}{r}18.2 \% \\
(8 / 44)\end{array}$ & $\begin{array}{l}55.0 \% \\
(22 / 40)\end{array}$ \\
\hline D & & $\begin{array}{l}33.3 \% \\
(12 / 36) \\
\end{array}$ & & $\begin{array}{l}22.5 \% \\
(9 / 40)\end{array}$ \\
\hline \multicolumn{5}{|c|}{ NOTE: Numbers in parentheses show the raw choice data and cell sizes } \\
\hline $\begin{array}{l}\text { Compromise effect } \\
\text { (ABC vs. BCD) }\end{array}$ & \multicolumn{2}{|c|}{$\begin{array}{l}+20.1 \%, p=.13 \\
(21 / 34 \text { vs. } 10 / 24)\end{array}$} & \multicolumn{2}{|c|}{$\begin{array}{c}+48.1 \%, p<.001 \\
(27 / 35 \text { vs. } 9 / 31)\end{array}$} \\
\hline
\end{tabular}

Table 1b. Results for the boxes of chocolate

\begin{tabular}{|c|c|c|c|c|}
\hline Choice set & $\begin{array}{r}\text { Bla } \\
\text { informa }\end{array}$ & ite & informa & ntation \\
\hline Options & $\mathrm{ABC}$ & $\mathrm{BCD}$ & $\mathrm{ABC}$ & $\mathrm{BCD}$ \\
\hline A & $\begin{array}{l}52.8 \% \\
(19 / 36)\end{array}$ & & $\begin{array}{l}45.5 \% \\
(20 / 44)\end{array}$ & \\
\hline B & $\begin{array}{l}30.6 \% \\
(11 / 36)\end{array}$ & $\begin{array}{l}72.2 \% \\
(26 / 36)\end{array}$ & $\begin{array}{l}40.9 \% \\
(18 / 44)\end{array}$ & $\begin{array}{l}52.5 \% \\
(21 / 40)\end{array}$ \\
\hline C & $\begin{array}{l}16.7 \% \\
(6 / 36)\end{array}$ & $\begin{array}{l}8.3 \% \\
(3 / 36)\end{array}$ & $\begin{array}{l}13.6 \% \\
(6 / 44)\end{array}$ & $\begin{array}{l}35.0 \% \\
(14 / 40)\end{array}$ \\
\hline D & & $\begin{array}{l}19.4 \% \\
(7 / 36)\end{array}$ & & $\begin{array}{l}12.5 \% \\
(5 / 40)\end{array}$ \\
\hline NOTE: $N$ & in parent & w the ray & lata and c & \\
\hline $\begin{array}{l}\text { Compromise effect } \\
\text { (ABC vs. BCD) }\end{array}$ & $\begin{array}{l}-25 \\
(11 /\end{array}$ & $\begin{array}{l}05 \\
\text { (29) }\end{array}$ & $\begin{array}{l}+15 \\
(18\end{array}$ & \\
\hline
\end{tabular}


Table 2

Study 2 results

Table 2a. Results for the computer products

\begin{tabular}{|c|c|c|c|c|}
\hline \multirow{2}{*}{$\mathrm{C}_{\text {Options }}^{\text {Choice set }}$} & \multicolumn{2}{|c|}{$\begin{array}{l}\text { Black-on-white } \\
\text { information presentation }\end{array}$} & \multicolumn{2}{|c|}{$\begin{array}{c}\text { Color } \\
\text { information presentation }\end{array}$} \\
\hline & $\mathrm{ABC}$ & $\mathrm{BCD}$ & $\mathrm{ABC}$ & $\mathrm{BCD}$ \\
\hline A & $\begin{array}{l}12.0 \% \\
(3 / 25)\end{array}$ & & $\begin{array}{l}9.1 \% \\
(3 / 33)\end{array}$ & \\
\hline B & $\begin{array}{l}64.0 \% \\
(16 / 25)\end{array}$ & $\begin{array}{l}20.0 \% \\
(5 / 25)\end{array}$ & $\begin{array}{l}78.8 \% \\
(26 / 33)\end{array}$ & $\begin{array}{l}20.0 \% \\
(7 / 35)\end{array}$ \\
\hline $\mathbf{C}$ & $\begin{array}{l}24.0 \% \\
(6 / 25)\end{array}$ & $\begin{array}{l}64.0 \% \\
(16 / 25)\end{array}$ & $\begin{array}{l}12.1 \% \\
(4 / 33)\end{array}$ & $\begin{array}{l}60.0 \% \\
(21 / 35)\end{array}$ \\
\hline $\mathrm{D}$ & & $\begin{array}{l}16.0 \% \\
(4 / 25)\end{array}$ & & $\begin{array}{l}20.0 \% \\
(7 / 35)\end{array}$ \\
\hline \multicolumn{5}{|c|}{ NOTE: Numbers in parentheses show the raw choice data and cell sizes } \\
\hline $\begin{array}{l}\text { Compromise effect } \\
\text { (ABC vs. BCD) }\end{array}$ & \multicolumn{2}{|c|}{$\begin{array}{l}+48.1 \%, p<.01 \\
(16 / 22 \text { vs. } 5 / 20)\end{array}$} & \multicolumn{2}{|c|}{$\begin{array}{c}+60.8 \%, p<.001 \\
(26 / 30 \text { vs. } 7 / 27)\end{array}$} \\
\hline
\end{tabular}

Table $2 \mathrm{~b}$. Results for the boxes of chocolate

\begin{tabular}{|c|c|c|c|c|}
\hline Choice set & $\begin{array}{r}\text { Bla } \\
\text { informa }\end{array}$ & $\begin{array}{l}\text { hite } \\
\text { sentation }\end{array}$ & informa & entation \\
\hline Options & $\mathrm{ABC}$ & BCD & $\mathrm{ABC}$ & $\mathrm{BCD}$ \\
\hline A & $\begin{array}{l}56.5 \% \\
(13 / 23) \\
\end{array}$ & & $\begin{array}{l}60.6 \% \\
(20 / 33) \\
\end{array}$ & \\
\hline B & $\begin{array}{l}30.4 \% \\
(7 / 23) \\
\end{array}$ & $\begin{array}{l}75.0 \% \\
(15 / 20)\end{array}$ & $\begin{array}{l}36.4 \% \\
(12 / 33)\end{array}$ & $\begin{array}{l}56.5 \% \\
(26 / 46)\end{array}$ \\
\hline $\mathbf{C}$ & $\begin{array}{l}13.0 \% \\
(3 / 23) \\
\end{array}$ & $\begin{array}{l}20.0 \% \\
(4 / 20) \\
\end{array}$ & $\begin{array}{l}3.0 \% \\
(1 / 33)\end{array}$ & $\begin{array}{l}37.0 \% \\
(17 / 46)\end{array}$ \\
\hline D & & $\begin{array}{l}5.0 \% \\
(1 / 20) \\
\end{array}$ & & $\begin{array}{r}6.5 \% \\
(3 / 46) \\
\end{array}$ \\
\hline NOTE: Num & parentl & ow the ra & data an & \\
\hline $\begin{array}{l}\text { Compromise effect } \\
\text { (ABC vs. BCD) }\end{array}$ & $\begin{array}{r}-8 . \\
(7 / 1 \\
\end{array}$ & $\begin{array}{l}.59 \\
/ 19)\end{array}$ & $\begin{array}{l}+32 \\
(12 /\end{array}$ & $\begin{array}{l}.05 \\
143)\end{array}$ \\
\hline
\end{tabular}


Table 3

\section{Study 3 results}

Table 3a. Results for the high accountability condition

\begin{tabular}{|c|c|c|c|c|c|c|}
\hline \multirow{2}{*}{$\begin{array}{r}\text { Choice } \\
\text { Set }\end{array}$} & \multicolumn{2}{|c|}{$\begin{array}{l}\text { Black-on-white } \\
\text { information } \\
\text { presentation }\end{array}$} & \multicolumn{2}{|c|}{$\begin{array}{l}\text { Color I } \\
\text { unique color format }\end{array}$} & \multicolumn{2}{|c|}{$\begin{array}{c}\text { Color II } \\
\text { same color format }\end{array}$} \\
\hline & $\mathrm{ABC}$ & $\mathrm{BCD}$ & $\mathrm{ABC}$ & $\mathrm{BCD}$ & $\mathrm{ABC}$ & $\mathrm{BCD}$ \\
\hline A & $\begin{array}{l}13.6 \% \\
(3 / 22)\end{array}$ & & $\begin{array}{l}43.8 \% \\
(7 / 16)\end{array}$ & & $\begin{array}{l}38.9 \% \\
(7 / 18)\end{array}$ & \\
\hline B & $\begin{array}{l}86.4 \% \\
(19 / 22)\end{array}$ & $\begin{array}{l}63.6 \% \\
(14 / 22)\end{array}$ & $\begin{array}{l}56.3 \% \\
(9 / 16)\end{array}$ & $\begin{array}{l}54.2 \% \\
(13 / 24)\end{array}$ & $\begin{array}{l}61.1 \% \\
(11 / 18)\end{array}$ & $\begin{array}{l}70.0 \% \\
(14 / 20)\end{array}$ \\
\hline $\mathbf{C}$ & $\begin{array}{l}0.0 \% \\
(0 / 22)\end{array}$ & $\begin{array}{l}31.8 \% \\
(7 / 22)\end{array}$ & $\begin{array}{l}\mathbf{0 . 0 \%} \\
(0 / 16)\end{array}$ & $\begin{array}{l}33.3 \% \\
(8 / 24)\end{array}$ & $\begin{array}{l}0.0 \% \\
(0 / 18)\end{array}$ & $\begin{array}{l}30.0 \% \\
(6 / 20)\end{array}$ \\
\hline $\mathrm{D}$ & & $\begin{array}{l}4.5 \% \\
(1 / 22) \\
\end{array}$ & & $\begin{array}{l}12.5 \% \\
(3 / 24)\end{array}$ & & $\begin{array}{l}0.0 \% \\
(0 / 20) \\
\end{array}$ \\
\hline \multicolumn{7}{|c|}{ NOTE: Numbers in parentheses show the raw choice data and cell sizes } \\
\hline $\begin{array}{c}\text { Compromise } \\
\text { effect } \\
\text { (ABC vs. } \\
\text { BCD) }\end{array}$ & \multicolumn{2}{|c|}{$\begin{array}{c}+33.3 \%, p<.01 \\
(19 / 19 \text { vs. } 14 / 21)\end{array}$} & \multicolumn{2}{|c|}{$\begin{array}{c}+38.1 \%, p<.05 \\
(9 / 9 \text { vs. } 13 / 21)\end{array}$} & \multicolumn{2}{|c|}{$\begin{array}{c}+30.0 \%, p<.05 \\
(11 / 11 \text { vs. } 14 / 20)\end{array}$} \\
\hline
\end{tabular}

Table 3b. Results for the low accountability condition

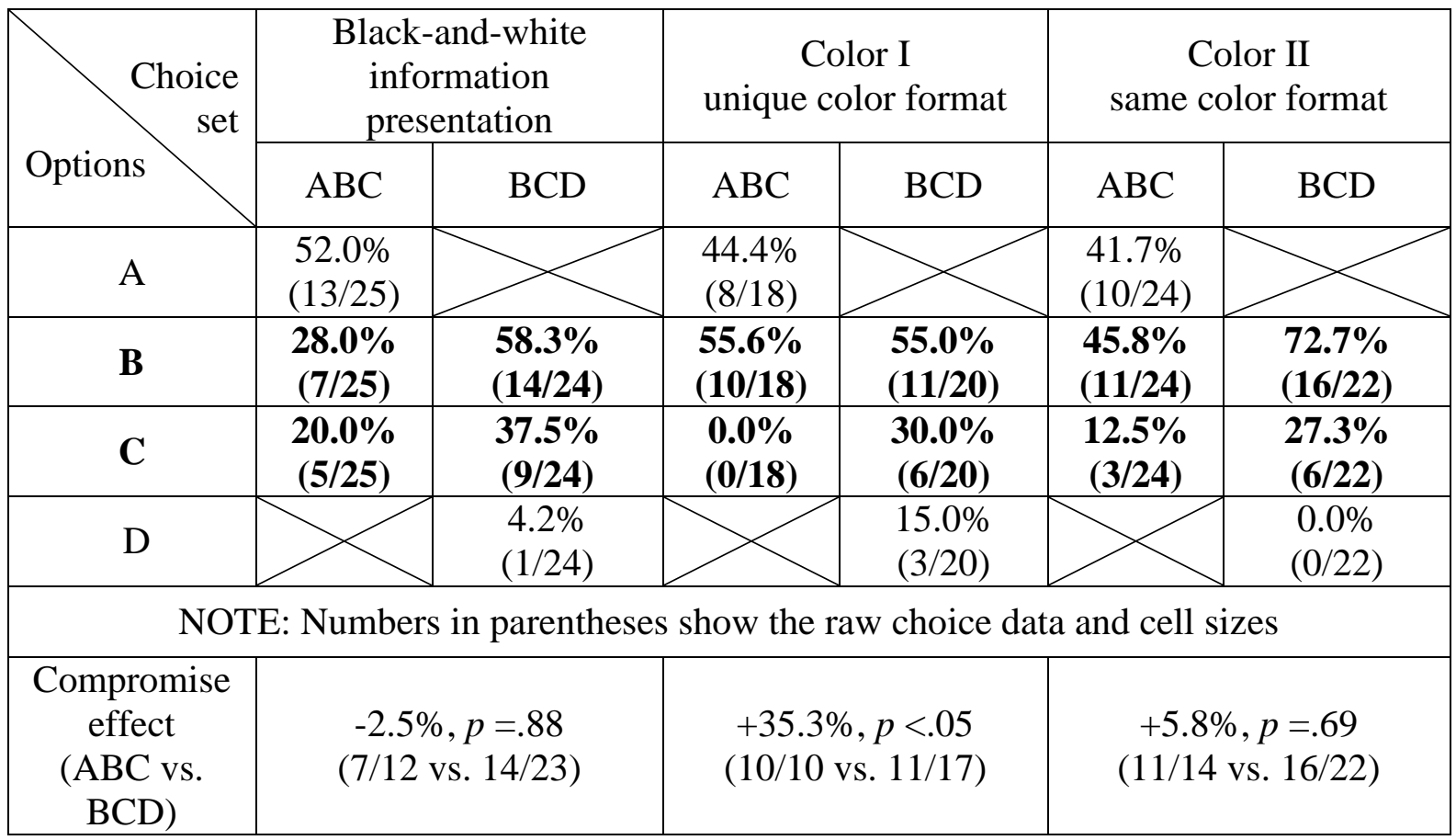


Table 4

Sale of Sushi

\begin{tabular}{|c|c|c|c|c|c|c|c|}
\hline \multirow{3}{*}{$\begin{array}{l}\text { Display } \\
\text { order }\end{array}$} & Date & \multicolumn{2}{|c|}{ Tuesday } & \multicolumn{2}{|c|}{ Wednesday } & \multicolumn{2}{|c|}{ Thursday } \\
\hline & $\begin{array}{l}\text { Experimental } \\
\text { condition }\end{array}$ & \multicolumn{2}{|c|}{ No color } & \multicolumn{2}{|c|}{$\begin{array}{c}\text { Colored } \\
\text { background }\end{array}$} & \multicolumn{2}{|c|}{ No color } \\
\hline & Sale & $\begin{array}{c}\text { Sale } \\
\#\end{array}$ & $\begin{array}{c}\text { Sale } \\
\%\end{array}$ & $\begin{array}{c}\text { Sale } \\
\#\end{array}$ & $\begin{array}{c}\text { Sale } \\
\%\end{array}$ & $\begin{array}{c}\text { Sale } \\
\#\end{array}$ & $\begin{array}{c}\text { Sale } \\
\%\end{array}$ \\
\hline \multirow{9}{*}{ Left } & Salmon Avocado & 47 & $27.5 \%$ & 17 & $11.5 \%$ & 54 & $26.9 \%$ \\
\hline & Teriyaki Chicken & 20 & $11.7 \%$ & 27 & $18.2 \%$ & 41 & $20.4 \%$ \\
\hline & Tuna & 16 & $9.4 \%$ & 20 & $13.5 \%$ & 13 & $6.5 \%$ \\
\hline & Chicken Katsu & 27 & $15.8 \%$ & 29 & $19.6 \%$ & 28 & $13.9 \%$ \\
\hline & Crumbed prawn & 20 & $11.7 \%$ & 23 & $15.5 \%$ & 20 & $10.0 \%$ \\
\hline & Spicy pork & 8 & $4.7 \%$ & 6 & $4.1 \%$ & 15 & $7.5 \%$ \\
\hline & Beef & 7 & $4.1 \%$ & 7 & $4.7 \%$ & 10 & $5.0 \%$ \\
\hline & Cream cheese & 10 & $5.8 \%$ & 7 & $4.7 \%$ & 6 & $3.0 \%$ \\
\hline & Seaweed & 5 & $2.9 \%$ & 3 & $2.0 \%$ & 3 & $1.5 \%$ \\
\hline \multirow[t]{2}{*}{ Right } & Mini sushi & 11 & $6.4 \%$ & 9 & $6.1 \%$ & 11 & $5.5 \%$ \\
\hline & Total & 171 & $100.0 \%$ & 148 & $100.0 \%$ & 201 & $100 \%$ \\
\hline
\end{tabular}


Figure 1

Percentage of High and Low NFU participants selecting a middle memory option

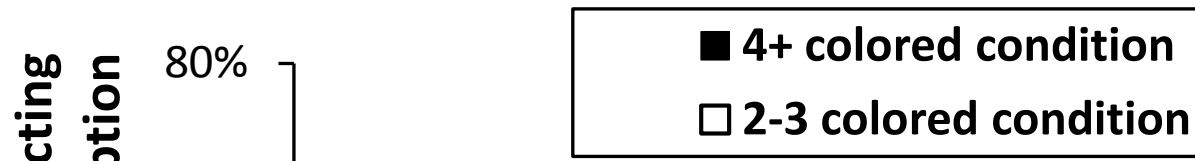

บิ

$\stackrel{2}{\frac{1}{0}}$

Н ํํㄹ $60 \%$

을 ำ

늘 은

을

पै ह $40 \%$

ט)

芯

동

บับ

ป

$20 \%$

$0 \%$

$50.0 \% \quad 50.5 \%$
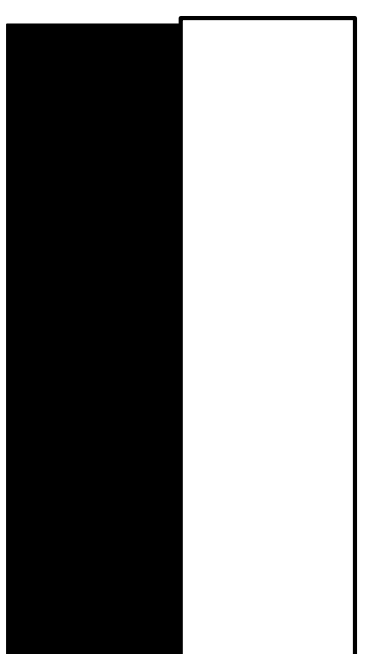

$61.5 \%$

Low NFU

High NFU 
Figure 2

The choice sets for Study 1a and 3

The computer options under the black-on-white condition: ABC condition

\begin{tabular}{lccc}
\hline & Computer 1 & Computer 2 & Computer 3 \\
Speed in GHz & 2.05 & 1.90 & 1.75 \\
Graphics Card & Okay & Good & Very good \\
\hline
\end{tabular}

The computer options under the black-on-white condition: BCD condition

\begin{tabular}{|cccc|}
\hline & Computer 1 & Computer 2 & Computer 3 \\
Speed in GHz & 1.90 & 1.75 & 1.60 \\
Graphics Card & Good & Very good & Excellent \\
\hline
\end{tabular}

The box of chocolate options under the color condition: ABC condition

\begin{tabular}{|cccc|}
\hline & Chocolate A & Chocolate B & Chocolate C \\
$\begin{array}{c}\text { Taste } \\
\text { (rated 1-10) }\end{array}$ & 8.5 & 8.0 & 7.5 \\
$\begin{array}{c}\text { Number of } \\
\text { different flavours }\end{array}$ & 2 & 4 & 6 \\
\hline
\end{tabular}

The box of chocolate options under color condition: BCD condition

\begin{tabular}{|cccc}
\hline & Chocolate A & Chocolate B & Chocolate C \\
$\begin{array}{c}\text { Taste } \\
\text { (rated 1-10) }\end{array}$ & 8.0 & 7.5 & 7.0 \\
$\begin{array}{c}\text { Number of } \\
\text { different flavours }\end{array}$ & 4 & 6 & 8 \\
\hline
\end{tabular}


Figure 3

Stimuli for Study 1B

Figure 3a. Different color condition

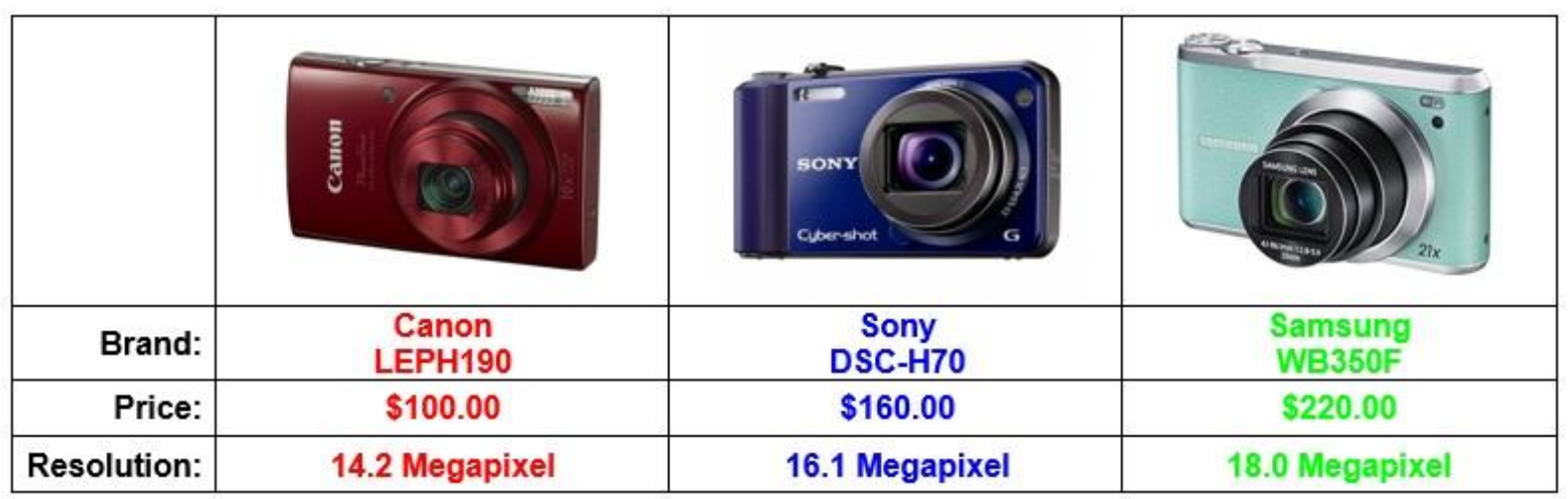

Figure 3b. Same color condition

\begin{tabular}{|r|c|c|c|}
\hline & & & \\
& & & \\
\hline Brand: & $\begin{array}{c}\text { Canon } \\
\text { LEPH190 }\end{array}$ & $\begin{array}{c}\text { Sony } \\
\text { DSC-H70 }\end{array}$ & $\begin{array}{c}\text { Samsung } \\
\text { WB350F }\end{array}$ \\
\hline Price: & $\$ 100.00$ & $\$ 160.00$ & $\$ 220.00$ \\
\hline Resolution: & 14.2 Megapixel & 16.1 Megapixel & 18.0 Megapixel \\
\hline
\end{tabular}


Figure 4

The Choice Sets Used in Study 3: ABC Condition Only

The box of chocolate options under the black-on-white condition

\begin{tabular}{|cccc|}
\hline & Chocolate A & Chocolate B & Chocolate C \\
$\begin{array}{c}\text { Taste } \\
\text { (rated 1-10) }\end{array}$ & 8.5 & 8.0 & 7.5 \\
$\begin{array}{c}\text { Number of } \\
\text { different flavours }\end{array}$ & 2 & 4 & 6 \\
\hline
\end{tabular}

The box of chocolate options under the Color I condition

\begin{tabular}{|cccc|}
\hline & Chocolate A & Chocolate B & Chocolate C \\
$\begin{array}{c}\text { Taste } \\
\text { (rated 1-10) } \\
\text { Number of } \\
\text { different flavours }\end{array}$ & 8.5 & 8.0 & 7.5 \\
\hline
\end{tabular}

The box of chocolate options under the Color II condition

\begin{tabular}{cccc}
\hline & Chocolate A & Chocolate B & Chocolate C \\
$\begin{array}{c}\text { Taste } \\
\text { (rated 1-10) }\end{array}$ & 8.5 & 8.0 & 7.5 \\
$\begin{array}{c}\text { Number of } \\
\text { different flavours }\end{array}$ & 2 & 4 & 6 \\
\hline
\end{tabular}


Figure 5

Sushi Sales Field Study

Figure 5a. Colored display condition

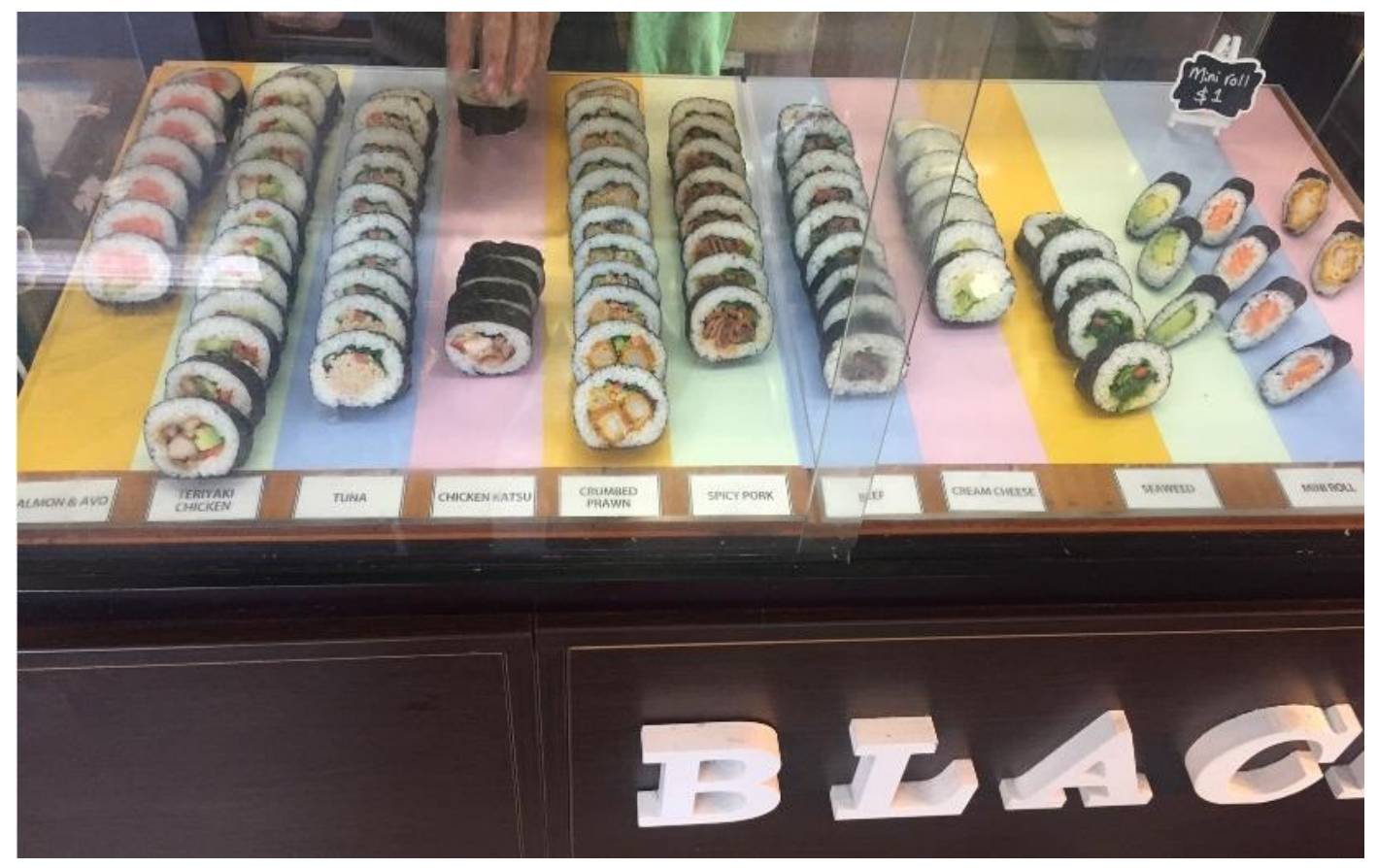

Figure 5b. No color display condition

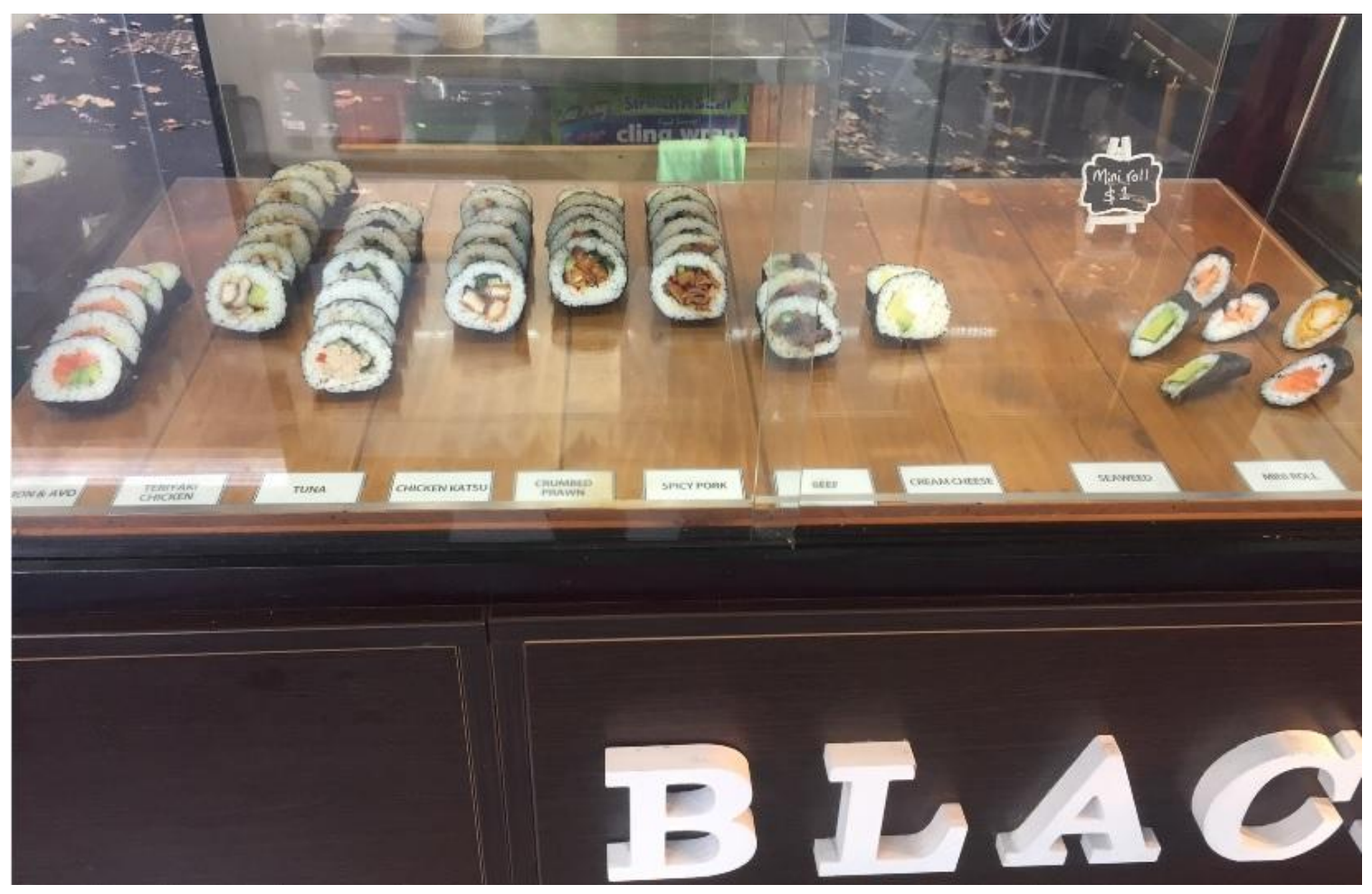


Figure 6

Stimuli for Study 4B

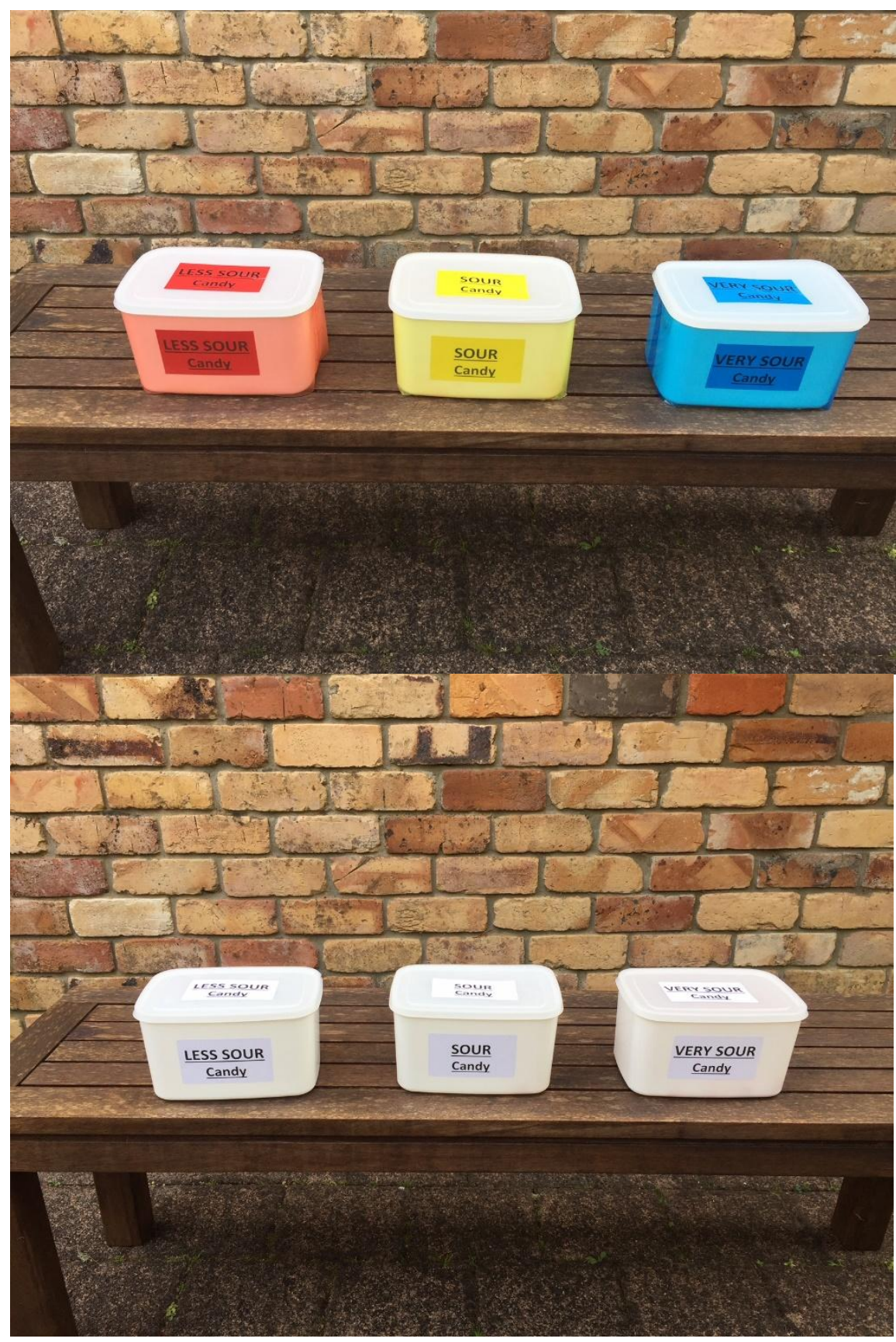


Appendix A

Examples of a search on Amazon.com
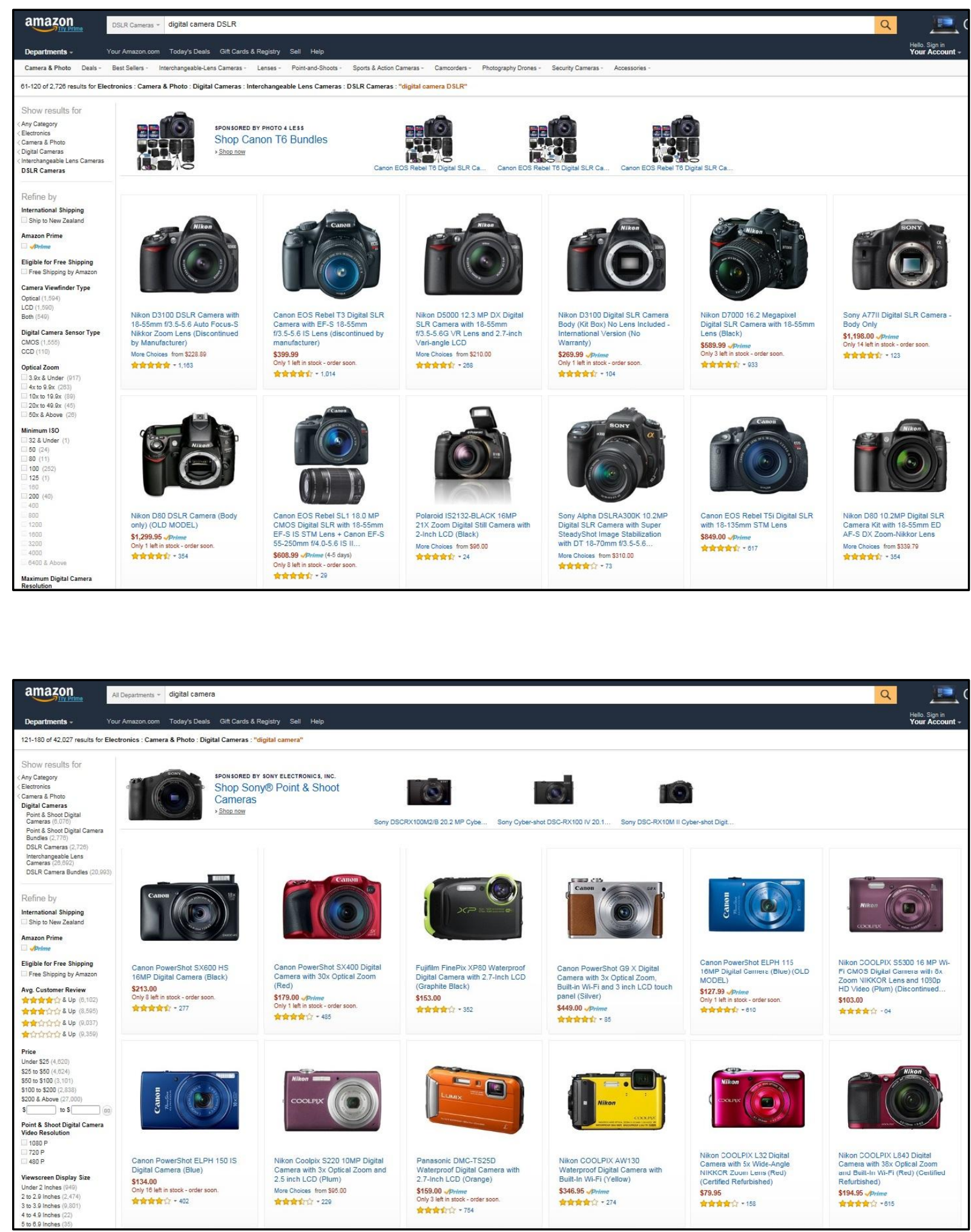